\title{
Sulfur solubility in reduced mafic silicate melts: Implications for the speciation and distribution of sulfur on Mercury
}

\author{
Olivier Namur ${ }^{\mathrm{a}, *}$, Bernard Charlier ${ }^{\mathrm{b}}$, Francois Holtz ${ }^{\mathrm{a}}$, Camille Cartier ${ }^{\mathrm{b}}$, \\ Catherine McCammon ${ }^{\mathrm{c}}$ \\ a Leibniz University of Hannover, Institute of Mineralogy, 30167 Hannover, Germany \\ b University of Liege, Department of Geology, 4000 Liege, Belgium \\ c Bayerisches Geoinstitut, University of Bayreuth, 95440 Bayreuth, Germany
}

\section{A R T I C L E I N F O}

\section{Article history:}

Received 8 January 2016

Received in revised form 11 May 2016

Accepted 15 May 2016

Available online $\mathrm{xxxx}$

Editor: C. Sotin

\section{Keywords:}

MESSENGER

oxygen fugacity

sulfide saturation

core

mantle

\begin{abstract}
A B S T R A C T
Chemical data from the MESSENGER spacecraft revealed that surface rocks on Mercury are unusually enriched in sulfur compared to samples from other terrestrial planets. In order to understand the speciation and distribution of sulfur on Mercury, we performed high temperature $\left(1200-1750^{\circ} \mathrm{C}\right)$, lowto high-pressure ( 1 bar to $4 \mathrm{GPa}$ ) experiments on compositions representative of Mercurian lavas and on the silicate composition of an enstatite chondrite. We equilibrated silicate melts with sulfide and metallic melts under highly reducing conditions (IW-1.5 to IW-9.4; IW = iron-wüstite oxygen fugacity buffer). Under these oxygen fugacity conditions, sulfur dissolves in the silicate melt as $\mathrm{S}^{2-}$ and forms complexes with $\mathrm{Fe}^{2+}, \mathrm{Mg}^{2+}$ and $\mathrm{Ca}^{2+}$. The sulfur concentration in silicate melts at sulfide saturation (SCSS) increases with increasing reducing conditions (from $<1 \mathrm{wt} . \% \mathrm{~S}$ at IW-2 to $>10 \mathrm{wt} . \% \mathrm{~S}$ at IW-8) and with increasing temperature. Metallic melts have a low sulfur content which decreases from $3 \mathrm{wt} . \%$ at IW-2 to 0 wt.\% at IW-9. We developed an empirical parameterization to predict SCSS in Mercurian magmas as a function of oxygen fugacity $\left(\mathrm{fO}_{2}\right)$, temperature, pressure and silicate melt composition. SCSS being not strictly a redox reaction, our expression is fully valid for magmatic systems containing a metal phase. Using physical constraints of the Mercurian mantle and magmas as well as our experimental results, we suggest that basalts on Mercury were free of sulfide globules when they erupted. The high sulfur contents revealed by MESSENGER result from the high sulfur solubility in silicate melt at reducing conditions. We make the realistic assumption that the oxygen fugacity of mantle rocks was set during equilibration of the magma ocean with the core and/or that the mantle contains a minor metal phase and combine our parameterization of SCSS with chemical data from MESSENGER to constrain the oxygen fugacity of Mercury's interior to IW-5.4 \pm 0.4 . We also calculate that the mantle of Mercury contains $7-11 \mathrm{wt} . \% \mathrm{~S}$ and that the metallic core of the planet has little sulfur $(<1.5 \mathrm{wt} . \% \mathrm{~S})$. The external part of the Mercurian core is likely to be made up of a thin $(<90 \mathrm{~km})$ FeS layer.
\end{abstract}

(c) 2016 Elsevier B.V. All rights reserved.

\section{Introduction}

Mercury is the innermost planet of our Solar system. It is made of a very large core ( 65 wt.\% of the planet; Hauck et al., 2013) and a thin mantle $(420 \pm 30 \mathrm{~km}$; Hauck et al., 2013; Padovan et al., 2015) dominated by olivine, orthopyroxene, clinopyroxene, \pm spinel and feldspar (Stockstill-Cahill et al., 2012; Charlier et al., 2013; Namur et al., 2016; Vander Kaaden and McCubbin, 2016). Building blocks of Mercury could be compositionally close to enstatite chondrite or bencubbinite chondrite mete-

\footnotetext{
* Corresponding author.

E-mail address: o.namur@mineralogie.uni-hannover.de (O. Namur).
}

orites (Brown and Elkins-Tanton, 2009; Malavergne et al., 2010, 2014; Chabot et al., 2014). The surface of Mercury is a secondary crust produced during volcanic eruptions (Weider et al., 2012; Byrne et al., 2013). Based on crater densities and chemical compositions, several provinces were described (Denevi et al., 2013; Weider et al., 2015): (1) the Northern Volcanic Plains (NVP) with calculated model ages ranging from 3.7 to $2.5 \mathrm{Ga}$ (Neukum et al., 2001; Marchi et al., 2009; Le Feuvre and Wieczorek, 2011; Ostrach et al., 2015); (2) the 4.0-3.7 Ga Smooth Plains (SP) and (3) the 4.2-4.0 Ga Inter-crater Plains and Heavily Cratered Terrains (IcP-HCT), which also contain a High-Mg Terrane (HMg).

Chemical data from the MESSENGER spacecraft show that Mercurian lavas are MgO-rich and have a low Fe content ( $<2$ wt.\%; Weider et al., 2014). They are also unusually enriched in sul- 


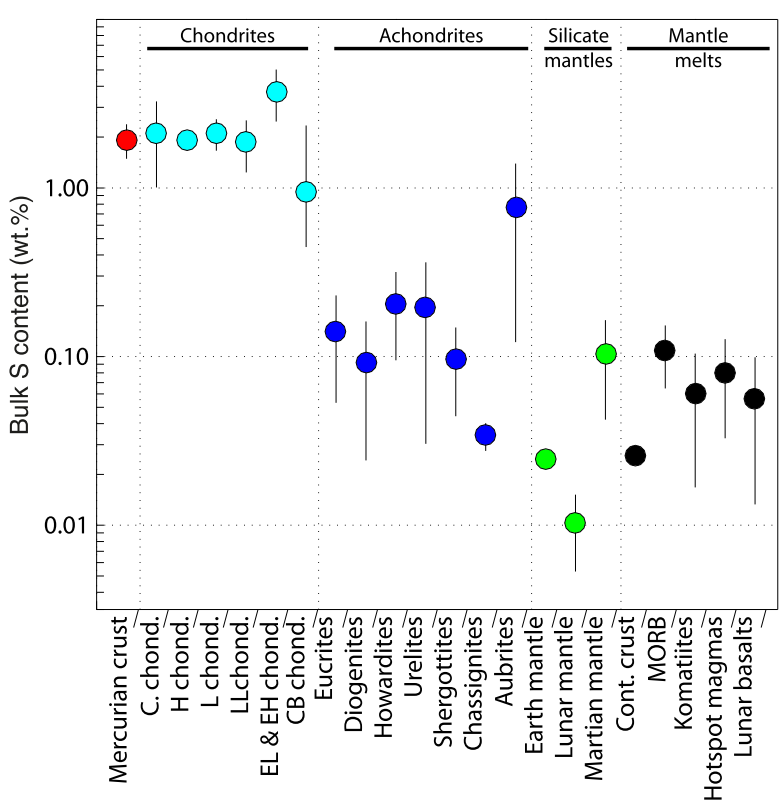

Fig. 1. Sulfur concentrations in the Mercurian crust, chondrites, achondrites, silicate mantles and crusts of terrestrial planets and primary mantle derived melts. Symbols show average concentrations and vertical bars show the $1 \sigma$ standard deviations. The data for the Mercurian crust were calculated using the MESSENGER data presented by Weider et al. (2015). The complete list of references and number of analyses used in the compilation are given in Appendix. $\mathrm{C}=$ Carbonaceous; Chond. = chondrite; Cont. = continental.

fur (Weider et al., 2015), with the highest sulfur concentrations ( $\sim 3$ wt.\% S) observed in HMg lavas (Peplowski et al., 2015). The sulfur content of Mercurian lavas is much higher than that observed in mantle rocks and lavas from the Earth, Mars and the Moon ( $<1$ wt.\% $\mathrm{S}$ ) and is as high as the bulk $\mathrm{S}$ content of chondrites (1-5 wt.\% S; Fig. 1). High sulfur concentrations in Mercurian lavas may result either from high sulfur solubility in magmas (Zolotov et al., 2013) and/or from transport of sulfide droplets from the mantle source regions to the surface of the planet (Malavergne et al., 2014). The first hypothesis is consistent with the absence of spectral evidence for sulfide minerals in surface rocks (McClintock et al., 2008; Izenberg et al., 2014) while the second could explain the correlations between $\mathrm{S}$ and $\mathrm{Ca}-\mathrm{Mg}$ observed in Mercurian lavas (Weider et al., 2012). Understanding the origin of high sulfur concentrations at the surface of Mercury is important to better constrain the structure of the planet and the distribution of sulfur amongst the different reservoirs (mantle, core and crust), the mechanisms of explosive volcanism (Kerber et al., 2009; Thomas et al., 2014a; Weider et al., 2016), and the formation of the hollows (sub-kilometer scale shallow depressions surrounded by bright deposits) which may have formed during sublimation of volatiles (Blewett et al., 2013; Thomas et al., 2014b).

The high sulfur concentrations in lavas, together with their low Fe contents and the large metal/silicate ratio of Mercury are strong evidence for accretion and differentiation of the planet under highly reducing conditions ( $<$ IW-3; IW = iron-wüstite oxygen fugacity buffer; Malavergne et al., 2010; McCubbin et al., 2012; Zolotov et al., 2013). However, any interpretation of magmatic processes on Mercury and, in particular, the behavior of sulfur in magmas are presently very difficult because of the very limited number of experimental studies performed under oxygen fugacity conditions relevant to Mercury (McCoy et al., 1999; Berthet et al., 2009; Chabot et al., 2014; Malavergne et al., 2014; Vander Kaaden and McCubbin, 2016). In this study, we present the results of 100 new, high-temperature, low- to high-pressure ( 1 bar to $4 \mathrm{GPa}$ ), experiments performed under highly reducing conditions (IW-1.5 to IW-9). Experiments were performed on compositions representative of the basalts and the mantle of Mercury. We investigate sulfur distribution in coexisting silicate melt, sulfide melt and metallic melt and use our experimental data to build a predictive model of sulfur solubility in silicate melt as a function of intensive parameters (temperature, pressure, oxygen fugacity). We then discuss sulfur transport from the mantle to the surface of Mercury, the redox conditions of the mantle and sulfur partitioning between the metallic core and the silicate mantle, with implications for the formation of a FeS layer at the mantle-core boundary.

\section{Experimental and analytical procedures}

\subsection{Choice and preparation of starting compositions}

Experiments were performed on three silicate compositions (Table 1) that were equilibrated with a Fe-bearing metallic phase and a sulfide phase. Silicate compositions were chosen to match (1) lavas of the Northern Volcanic Plains (NVP), (2) the high-Mg terrane $(\mathrm{HMg})$ of the IcP-HCT and (3) a composition representative of the silicate fraction of an enstatite chondrite (EH). NVP and $\mathrm{HMg}$ compositions are based on geochemical data presented by Weider et al. (2012). For NVP, we used 34 X-Ray Spectroscopy (XRS) measurements and calculated median values for the $\mathrm{Mg} / \mathrm{Si}$, $\mathrm{Al} / \mathrm{Si}$ and $\mathrm{Ca} / \mathrm{Si}$ ratios and re-calculated the compositions on an oxide basis. For minor elements $\left(\mathrm{TiO}_{2}, \mathrm{MnO}\right.$ and $\left.\mathrm{K}_{2} \mathrm{O}\right)$, we used data from Nittler et al. (2011) and Peplowski et al. (2012). We considered a Na/Si ratio of 0.20 (Peplowski et al., 2014), leading to $\sim 7$ wt.\% $\mathrm{Na}_{2} \mathrm{O}$ in the NVP composition. For some experiments, we also used a Na-free NVP composition. For HMg, we prepared a starting composition corresponding to the median composition of the High-Mg terrane of the IcP-HCT. We used 49 XRS measurements with a $\mathrm{Mg} / \mathrm{Si}$ ratio greater than 0.6 . We considered a $\mathrm{Na} / \mathrm{Si}$ ratio of 0.06 ( $\sim 2.7$ wt.\% $\mathrm{Na}_{2} \mathrm{O}$ ) and $0.1 \mathrm{wt} . \% \mathrm{~K}_{2} \mathrm{O}$. For the EH starting material, we used the silicate composition of the Indarch meteorite (McCoy et al., 1999; Berthet et al., 2009).

Silicate compositions were produced from high-purity oxides and carbonates. Mixtures were decarbonated at $900^{\circ} \mathrm{C}$ for $10 \mathrm{hrs}$. The reagents were then mixed under ethanol. Silicate compositions were mixed with metallic and sulfide materials produced with FeS, $\mathrm{S}$ and $\mathrm{Fe}$ in different proportions (Table 1). For the sulfur source, we used $\mathrm{FeS}, \mathrm{FeS}+\mathrm{S}$ or $\mathrm{S}$ because $\mathrm{CaS}$ was not stable during preparation of the starting materials. We used several combinations of the silicate/metal/sulfide mixture (Table 1; Supplementary Dataset 1). The total Fe content in our experiments ranges from 15-25 wt.\%, which is lower than the bulk Fe content of the planet ( 65 wt.\%; Hauck et al., 2013) and higher than the Fe content of Mercurian lavas (0-2 wt.\%; Weider et al., 2014).

The intrinsic oxygen fugacity $\left(\mathrm{fO}_{2}\right)$ of the samples was reduced by adding $\mathrm{Si}$ metal powder to the silicate starting material (Berthet et al., 2009; Cartier et al., 2014a; Malavergne et al., 2014). In most experiments, we varied the $\mathrm{Si} / \mathrm{SiO}_{2}$ ratio $(0-0.5)$ in order to control $\mathrm{fO}_{2}$ without affecting cation ratios of the starting compositions. In other experiments, we added additional Si (total of 20 and 50 wt.\% Si) to reach highly reducing conditions.

\subsection{Experiments, analytical methods and oxygen fugacity}

Low-pressure (1 bar) experiments were performed in a Gero gas-mixing furnace in evacuated silica tubes at the University of Hannover. Medium-pressure experiments (0.1-0.3 GPa) were performed in large volume internally heated pressure vessels (IHPV) at the University of Hannover (Germany). Argon was used as the pressure medium. High-pressure experiments (1 to $4 \mathrm{GPa}$ ) 
Table 1

Starting compositions for the experiments.

\begin{tabular}{|c|c|c|c|c|c|c|c|c|c|c|}
\hline & \multicolumn{6}{|c|}{ MESSENGER data of Mercury's basalts ${ }^{\mathrm{a}}$} & \multicolumn{4}{|c|}{ Calculated oxide compositions } \\
\hline & $\mathrm{Mg} / \mathrm{Si}$ & $\mathrm{Al} / \mathrm{Si}$ & $\mathrm{Ca} / \mathrm{Si}$ & & & & $\mathrm{SiO}_{2}$ & $\mathrm{Al}_{2} \mathrm{O}_{3}$ & $\mathrm{MgO}$ & $\mathrm{CaO}$ \\
\hline NVP & $0.309 \pm 0.13$ & $0.263 \pm 0.07$ & $0.156 \pm 0.04$ & & & & $62.41 \pm 3.75$ & $14.65 \pm 3.36$ & $14.85 \pm 5.0$ & $6.19 \pm 1.57$ \\
\hline High-Mg IcP-HCT & $0.682 \pm 0.07$ & $0.189 \pm 0.07$ & $0.211 \pm 0.04$ & & & & $53.06 \pm 2.36$ & $8.85 \pm 3.11$ & $28.05 \pm 2.39$ & $7.32 \pm 1.33$ \\
\hline \multirow[t]{3}{*}{$\mathrm{EH}$} & - & - & - & & & & - & - & - & - \\
\hline & \multicolumn{10}{|c|}{ Synthetic silicate starting compositions including $\mathrm{Na}_{2} \mathrm{O}$ and minor elements ${ }^{\mathrm{b}}$ (mixture of oxides and carbonates) } \\
\hline & $\mathrm{SiO}_{2}$ & $\mathrm{TiO}_{2}$ & $\mathrm{Al}_{2} \mathrm{O}_{3}$ & $\mathrm{MnO}$ & $\mathrm{MgO}$ & $\mathrm{CaO}$ & $\mathrm{Na}_{2} \mathrm{O}$ & $\mathrm{K}_{2} \mathrm{O}$ & $\mathrm{NiO}$ & $\mathrm{Cr}_{2} \mathrm{O}_{3}$ \\
\hline NVP & 58.59 & 0.40 & 13.72 & 0.20 & 13.91 & 5.79 & 6.99 & 0.20 & 0.10 & 0.10 \\
\hline High-Mg IcP-HCT & 52.56 & 0.40 & 8.77 & 0.20 & 27.78 & 7.26 & 2.74 & 0.08 & 0.10 & 0.10 \\
\hline $\mathrm{EH}$ & 62.42 & 0.10 & 2.70 & 0.10 & 30.81 & 1.77 & 1.70 & 0.20 & 0.10 & 0.10 \\
\hline \multicolumn{11}{|c|}{ Silicate-metal-sulfide ratios used in experiments ${ }^{c}$} \\
\hline & Silicate & FeS & $\mathrm{Fe}$ & $\mathrm{S}$ & & & & & & \\
\hline A & 0.70 & 0.25 & 0.05 & - & & & & & & \\
\hline $\mathrm{B}$ & 0.90 & - & 0.05 & 0.05 & & & & & & \\
\hline C & 0.60 & 0.25 & 0.05 & 0.10 & & & & & & \\
\hline D & 0.85 & - & 0.05 & 0.10 & & & & & & \\
\hline $\mathrm{E}$ & 0.70 & - & 0.15 & 0.15 & & & & & & \\
\hline $\mathrm{F}$ & 0.55 & 0.35 & 0.05 & 0.05 & & & & & & \\
\hline
\end{tabular}

a Calculated using elemental ratios from MESSENGER (Weider et al., 2012).

b $\mathrm{K}_{2} \mathrm{O}$ and $\mathrm{Na}_{2} \mathrm{O}$ calculated from Peplowski et al. (2012, 2014); $\mathrm{TiO}_{2}$ and $\mathrm{MnO}$ contents based on Weider et al. (2014). EH composition from Berthet et al. (2009).

c See details about the silicate-metal mixtures used in each experiment as well as the content of Si metal added to the starting material in Supplementary Dataset 1.

were performed at the Bayerisches Geoinstitut (BGI; Germany) in $0.5^{\prime \prime}$ piston cylinder apparatuses. A comprehensive description of the experimental methods and conditions with details of temperature and pressure calibration and run procedures is included in the Experimental Methods Online (Appendix and Supplementary Dataset 1). Experiments were run for 4-8 hrs, which was shown to be ideal to reach equilibrium and to avoid significant oxidation of metal Si (Vander Kaaden and McCubbin, 2016).

Quantitative analyses were performed using a CAMECA SX100 electron microprobe analyzer (EMPA) at the University of Hannover (see details in Appendix). Repeated analyses of international standards and standard deviations of measurements for our experimental products indicate errors of less than $5 \%$ for major elements and $10 \%$ for minor elements. Errors on sulfur concentrations in silicate melts are more difficult to estimate because no glass standard with high $\mathrm{S}$ content exists. Accurate calibrations on pyrite and the high reproducibility of our measurements suggest errors of less than $10 \%$. Raman spectroscopy was performed with a confocal Bruker Senterra micro-Raman spectrometer equipped with an Olympus BX 51 microscope and an Andor DU420-OE CCD camera. The spot size for analyses was $\sim 1 \mu \mathrm{m}$.

The presence of silicate melt (Sil) and Fe-rich metallic melt (Met) in most of our experiments constrain the intrinsic $f_{2}$ of the experiment by the equilibrium:

$\mathrm{Fe}^{\mathrm{Met}}+1 / 2 \mathrm{O}_{2}=\mathrm{FeO}^{\mathrm{Sil}}$

For most experiments, the $\mathrm{FeO}$ content of the silicate melt is too low ( $<0.1$ wt.\%) to be accurately measured by EMPA and the activity coefficient of $\mathrm{FeO}$ in the silicate melt is poorly estimated in FeO-poor magmas (Wykes et al., 2015). We have therefore calculated the $\mathrm{fO}_{2}$ of the experiments using the following equilibrium (Cartier et al., 2014a):

$\mathrm{Si}^{\mathrm{Met}}+\mathrm{O}_{2}=\mathrm{SiO}_{2} \mathrm{Sil}$

A comprehensive description of the method of calculation is given in Appendix. Errors on calculated oxygen fugacity (Fig. 2) take into account the $1 \sigma$ standard deviation of repeated measurements (silicate melt and metal melt). Absolute errors are estimated using thermodynamic properties of the elements and oxides involved in Eq. (2) (Robie and Hemingway, 1995) and are lower than $0.5 \log$ unit.

\section{Experimental results}

\subsection{Phase assemblages and microstructures}

All experiments show a multi-component assemblage dominated by quenched silicate melt $\left(\mathrm{X}_{\mathrm{Sil}}\right.$ : 0.51-0.88), sulfide melt $\left(\mathrm{X}_{\text {Sul }}\right.$ : 0.01-0.42) and metallic melt ( $\mathrm{X}_{\text {Met }}: 0-0.26$; Fig. 2a; Supplementary Dataset 1 ), where $\mathrm{X}_{\text {Sil }}, \mathrm{X}_{\text {Sul }}$ and $\mathrm{X}_{\text {Met }}$ are the weight fractions of the different melts. Subliquidus experiments also show silicate minerals. In most experiments, forsterite is the liquidus phase (Fig. 2b) while enstatite is observed in some high-pressure experiments ( $\geq 2 \mathrm{GPa}$; Fig. 2a) and in medium-pressure (0.1-0.3 GPa) experiments performed on the Na-free NVP composition (Fig. 2c). In the silicate fraction of the experiments, the proportion of silicate melt ranges from 0.78 to 1.00 , while the forsterite and enstatite proportions range from $0-0.22$ and $0-0.14$, respectively. Except in some high-pressure experiments, no quench microstructure is observed in the silicate melt.

Enstatite and forsterite form homogeneous, unzoned, euhedral crystals with sizes ranging from 5 to $500 \mu \mathrm{m}$ (Figs. 2a and b). They are homogeneously distributed in the low- to medium-pressure experimental charges while they are usually observed along the edges of the capsule in piston cylinder experiments. Quenched metal and sulfide melts generally form large (50 to $500 \mu \mathrm{m}$ ), subspherical globules attesting that they represent quenched melt droplets formed at high temperature. They are very often distributed along the sides of the experimental capsule although abundant sulfide and metal droplets are also observed in the central part of the samples. In many experiments, we observe largesize $(>100 \mu \mathrm{m})$ composite globules with a core made of metallic melt and a rim dominated by sulfide melt (Fig. 2a), which coexist with smaller globules of sulfide or metal melt. In highly reducing experiments (e.g. IW-6 to IW-9), we also observe the presence of $\mathrm{Mg}$ - and Ca-rich sulfide melts forming large pools (Fig. 2d). In contrast to silicate melts, sulfide melts usually show $\mu \mathrm{m}$-scale tabletor lamella-shaped quench microstructures which appear to be Fe-, $\mathrm{Mn}-, \mathrm{Cr}$-bearing monosulfide crystals. Submicrometric globules of metallic melt, and possibly sulfide melts, are also commonly observed. In addition to the presence of large metal and sulfide globules, some experiments (especially in IHPV) show abundant submicrometric globules of metallic melt homogeneously distributed in the silicate melt. We interpret these small globules as the result of inefficient coarsening of the metal globules (Ertel et al., 2006; Malavergne et al., 2016). 

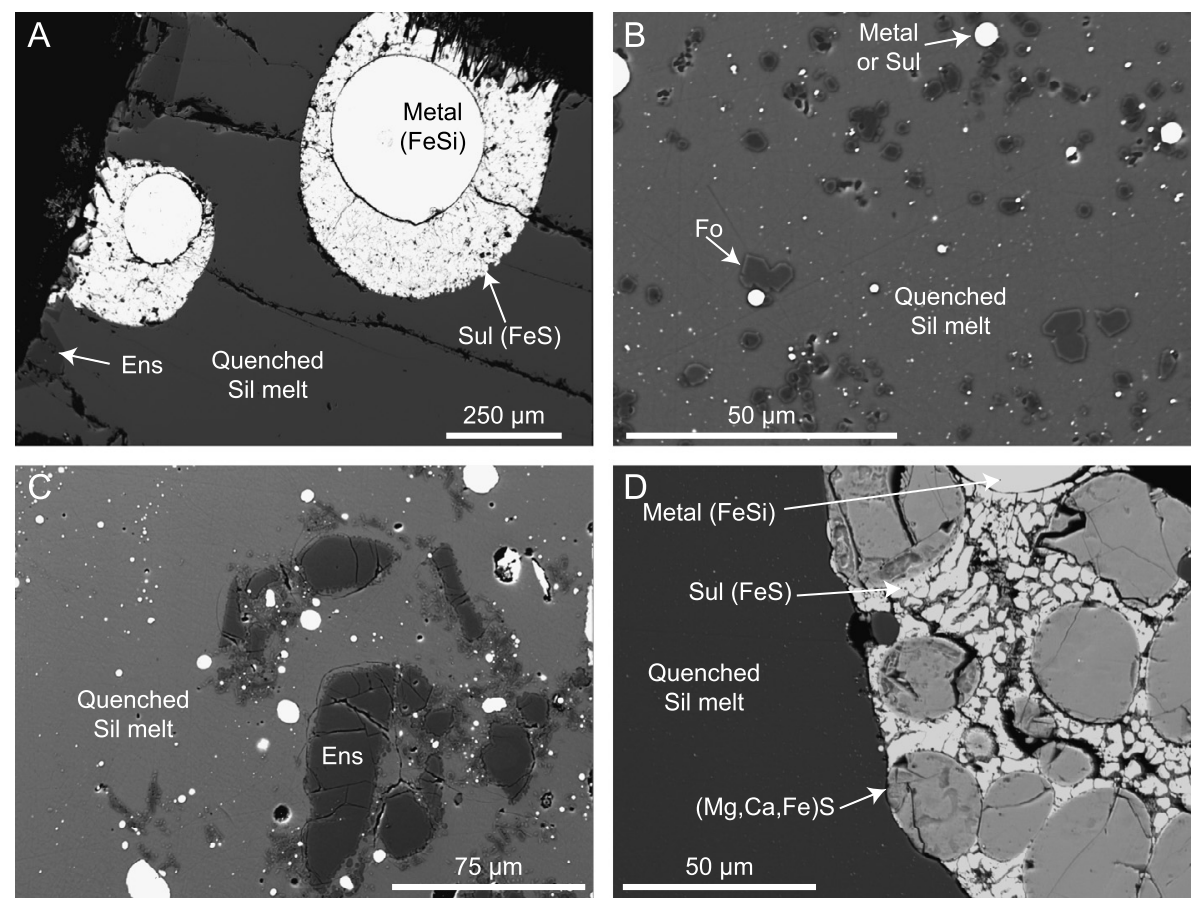

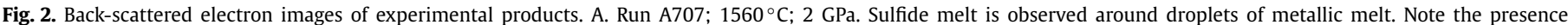

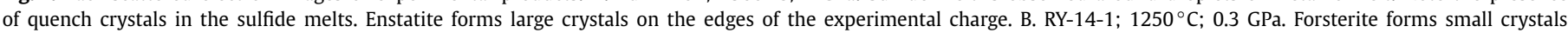

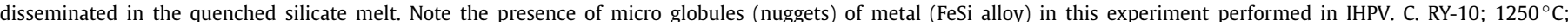

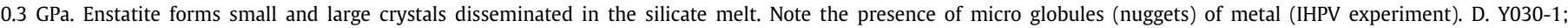
$1420^{\circ} \mathrm{C}$; $0.1 \mathrm{GPa}$. Note the presence of $(\mathrm{Mg}, \mathrm{Ca}, \mathrm{Fe}) \mathrm{S}$ globules in a matrix of FeS melt. Sil = silicate; Sul = sulfide; Ens = enstatite; Fo = forsterite.

\subsection{Major element compositions of the experiments and sulfur concentration in silicate melts}

In the following, we present the compositions of the phases obtained in the experimental runs. We express the chemical analyses of silicate melts as cations (wt.\%) rather than as oxides because under highly reducing conditions sulfur replaces oxygen in the silicate melt structure (O'Neill and Mavrogenes, 2002). In the less reduced super-liquidus or near-liquidus experiments, the major element compositions of the silicate melts (Supplementary Dataset 2; Supplementary Fig. S1) are relatively similar to those of starting silicate compositions (Table 1). Under more reduced conditions, the presence of abundant sulfur in the silicate melt dilutes all major elements compared to the starting compositions but cation ratios remain relatively constant. In sub-liquidus experiments, the crystallization of forsterite or enstatite changes the composition of the residual silicate melts by decreasing the Mg content (e.g. 7 to 3 wt.\% from 1310 to $1200^{\circ} \mathrm{C}$ for the NVP composition) and increasing the Si content ( 26 to 30 wt.\% from 1310 to $1200^{\circ} \mathrm{C}$ ). In the most reducing experiments (IW- 6 to IW-9), the formation of ( $\mathrm{Mg}, \mathrm{Ca}, \mathrm{Fe}) \mathrm{S}$ sulfide melt globules (see below) also affects the $\mathrm{Ca}$ and $\mathrm{Mg}$ contents of the silicate melts. With increasing reducing conditions, Fe decreases from $6.57 \mathrm{wt} . \%$ to $0.01 \mathrm{wt} . \%$ in the silicate melt, with most experiments having Fe contents below 0.5 wt.\%. Calculated oxygen contents decrease from 50 to 39 wt.\% in the silicate liquid. Three experiments show silicate melts with remarkably high Si contents (>35 wt.\%) and correspond to the experiments in which the highest amounts of Si metal were added to the starting materials. This indicates partial oxidation of metal Si during some experiments (Vander Kaaden and McCubbin, 2016). Mineral compositions match forsterite and enstatite endmembers.

The sulfur content at sulfide saturation (SCSS) in silicate melts is shown and compared with relevant literature data in Fig. 3a. Depending on $\mathrm{fO}_{2}$ conditions, pressure and temperature, $\mathrm{S}$ in silicate melts ranges from $<0.5 \mathrm{wt} . \%$ to $\sim 18 \mathrm{wt} . \%$. There is an obvious in- crease of SCSS with decreasing $f \mathrm{O}_{2}$. For experiments performed in a restricted range of temperature (e.g. $1350-1500^{\circ} \mathrm{C}$ ), SCSS increases from $<0.5$ wt.\% to 13 wt.\% from IW-1.5 to IW-8.5. An identical effect is observed by Chabot et al. (2014) in experiments performed at $1500^{\circ} \mathrm{C}$ and a pressure of 1 bar. At any given oxygen fugacity, SCSS also increases with temperature. This effect becomes stronger with decreasing $\mathrm{fO}_{2}$. At $\mathrm{fO}_{2}$ conditions $<\mathrm{IW}-6$, SCSS increases by a factor of 3 between experiments $<1350^{\circ} \mathrm{C}$ and experiments $>1500^{\circ} \mathrm{C}$. This magnitude is identical to that observed in previous experiments (Vander Kaaden and McCubbin, 2015a). The effect of pressure on SCSS is more difficult to assess because high-pressure experiments also correspond to the experiments performed at the highest temperatures, which makes it difficult to isolate the individual effect of these two parameters. The effect of the silicate melt composition (Fig. S1) is more subtle and will be discussed and modeled below. Overall, our new experiments reproduce data from previous studies (McCoy et al., 1999; Berthet et al., 2009; Malavergne et al., 2014), but they significantly expand the investigated range of $\mathrm{fO}_{2}$, temperature, pressure and melt compositions. Unlike previous studies, we produced silicate melts with $>10$ wt.\% S. Such high S concentrations have not been described yet in complex, multi-component, silicate melts but were experimentally produced in simplified systems (e.g. diopside melt; Vander Kaaden and McCubbin, 2015a).

The metallic phase in equilibrium with the silicate melt is dominated by Fe (69-100 wt.\%), Si (0-29 wt.\%), with minor $\mathrm{Cr}$ (0-3 wt.\%) and $\mathrm{Ni}(0-8$ wt.\%; Fig. 3b). Although compositional variability was observed in some experiments, a single, homogeneous, metallic melt is observed in most experiments. The sulfur content of the metal melt is low and decreases continuously with $\mathrm{fO}_{2}$ from $\sim 2.2 \mathrm{wt} . \%$ at IW-3.5 to 0 wt.\% at IW-9, leading to a decrease of $D_{\mathrm{S}}^{\mathrm{Met} / \mathrm{Sil}}$ from $\sim 2.5$ to 0.01 . In the most oxidized experiments ( $>$ IW-2.5), we observe higher $D_{\mathrm{S}}^{\mathrm{Met} / \mathrm{Sil}}$ values (5-20). The totals in the metallic phase increase from 94 to $100 \%$ with increasing $\mathrm{Si}$ content (and decreasing $\mathrm{S}$ content) suggest- 

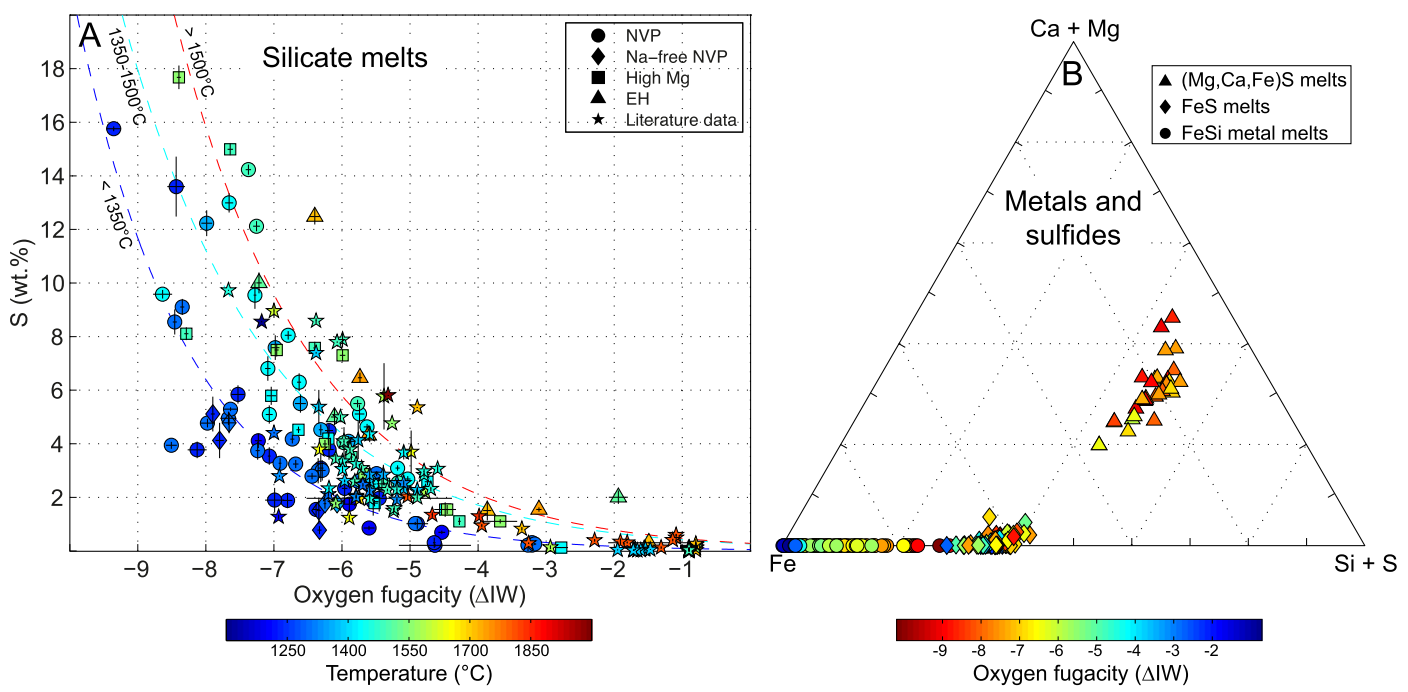

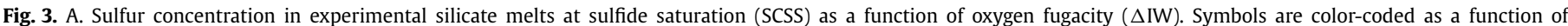

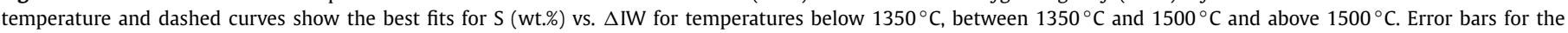

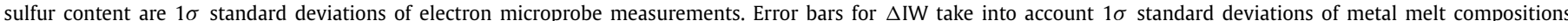

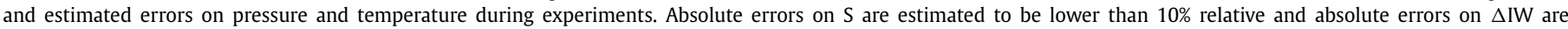

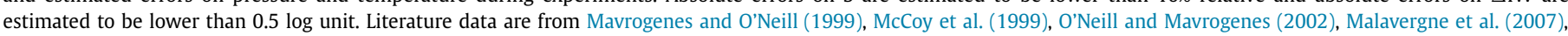

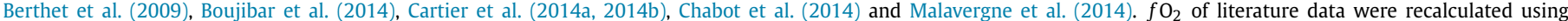

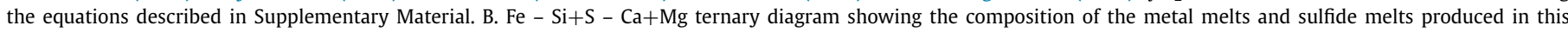

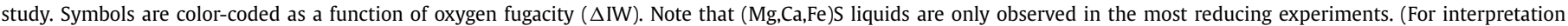
of the colors in this figure, the reader is referred to the web version of this article.)

ing a lower concentration of dissolved carbon (Li et al., 2015). The sulfide phase observed in the majority of our experiments is dominated by Fe (54-69 wt.\%) and S (27-39 wt.\%), with minor Ti (0.0-4.5 wt.\%), Mn (0.0-2.3 wt.\%), Mg (0.0-4.1 wt.\%), Ca (0.0-2.8 wt.\%), $\mathrm{Cr}(0.1-3.2$ wt.\%) and $\mathrm{Ni}(0.0-3.0 \mathrm{wt} . \%)$, and has a Fe/S ratio close to $1\left(\mathrm{Fe}_{0.91} \mathrm{~S}_{1.09}\right.$ to $\mathrm{Fe}_{1.13} \mathrm{~S}_{0.87}$; average $\left.\mathrm{Fe}_{1.0} \mathrm{~S}_{1.0}\right)$. Part of this compositional variability is attributed to the formation of quench phases and formation of monosulfide crystals. Some experiments show a second sulfide melt with lower Fe content (10-33 wt.\%) but higher Mg (7-30 wt.\%), Mn (0-10 wt.\%), Ca (2-35 wt.\%) and S (38-49 wt.\%) concentrations and an average composition of $\left(\mathrm{Fe}_{0.25} \mathrm{Mn}_{0.03} \mathrm{Mg}_{0.60} \mathrm{Ca}_{0.14}\right) \mathrm{S}_{0.98}$.

\subsection{Sulfur speciation in silicate melts}

Raman spectra (see analytical details in Appendix) in quenched FeS sulfide melts show very low intensity with dominant peaks at 310 and $360 \mathrm{~cm}^{-1}$ (Fe-S vibration). Spectra in (Fe,Mg,Ca)S sulfide globules are significantly more intense with higher signal-tonoise ratios (Fig. 4a). They display a major peak at $285 \mathrm{~cm}^{-1}$ and a prominent shoulder at $350 \mathrm{~cm}^{-1}$. With increasing $(\mathrm{Mg}+\mathrm{Ca}) / \mathrm{Fe}$ ratio, a peak at $210 \mathrm{~cm}^{-1}$ progressively appears. Similar peak positions were identified in oldhamite $(\mathrm{CaS})$ and niningerite ((Mg,Fe)S; Avril et al., 2013). Raman spectra in silicate melts were acquired with a $1 \mu \mathrm{m}$ spot and care was taken to avoid contamination from micro-nuggets of sulfide and metal melts or crystals. Raman spectra show a major peak at $\sim 480 \mathrm{~cm}^{-1}$ and broad peaks at $\sim 750 \mathrm{~cm}^{-1}$ and $\sim 1050 \mathrm{~cm}^{-1}$ which are assigned to symmetric stretching vibrations of Si-O-Si (McMillan and Wolf, 1995). Sulfur in silicate melt generally forms complexes with $\mathrm{Fe}^{2+}$ (O'Neill and Mavrogenes, 2002) which is shown by Raman vibration peaks occurring at $\sim 360 \mathrm{~cm}^{-1}$. However, with increasing sulfur content in the silicate glass, we observe the appearance of increasingly intense peaks at $285 \mathrm{~cm}^{-1}$ and $350 \mathrm{~cm}^{-1}$ (Fig. 4b). The positions of these two peaks are identical to those observed in (Fe,Mg,Ca)S sulfide globules. In our experiments where the sulfur content of the glasses significantly exceeds the total amount of $\mathrm{Fe}^{2+}$, we interpret these peaks as an evidence for the formation of $\mathrm{MgS}$ and $\mathrm{CaS}$ com- plexes in reducing silicate melts. This is in agreement with previous studies on S-bearing melts at reducing conditions (Fogel, 2005; Métrich et al., 2009).

\section{Modeling sulfur solubility in silicate melts}

Several predictive models of SCSS in silicate melts have been previously published and allow prediction of SCSS in magmas relevant to the Earth or Mars (Holzheid and Grove, 2002; Li and Ripley, 2005; Righter et al., 2009; Ding et al., 2014). These models do not reproduce our experimental results (Supplementary Fig. S2) because they were calibrated on the basis of oxidized experiments only. The new model of Malavergne et al. (2014) was designed to estimate SCSS in reducing magmas. It was, however, calibrated on a very limited number of experiments and is not accurate enough to reproduce our data, possibly due to the smaller ranges of composition, temperature and pressure used in their calibration dataset. The recent thermodynamic expression of Wykes et al. (2015) captures extremely well the important effect of FeO (controlled by $\mathrm{fO}_{2}$ during silicate-metal equilibration; Gaillard and Scaillet, 2009) on SCSS and therefore predicts the high SCSS observed for most of our experiments. A robust application of this model is unfortunately hampered by its extreme sensitivity to minor changes of the melt FeO content which are unconstrained for Mercurian magmas (Weider et al., 2014). There is therefore a need for a new, accurate, predictive model of SCSS, calibrated over a large range of pressure, temperature, melt compositions and $f \mathrm{O}_{2}$, which can be used to model the sulfur behavior in Mercurian magmas.

At reducing conditions $(<\mathrm{IW}+3)$, sulfur $\left(\mathrm{S}^{2-}\right)$ replaces oxygen $\left(\mathrm{O}^{2-}\right)$ on the anion sublattice of the silicate melt following the expression (O'Neill and Mavrogenes, 2002):

$\mathrm{O}^{2-}+\frac{1}{2} \mathrm{~S}_{2}=\mathrm{S}^{2-}+\frac{1}{2} \mathrm{O}_{2}$

The equilibrium constant of Eq. (3) can be described as:

$\ln \mathrm{K}_{(3)}=\ln a_{S^{2-}}^{\mathrm{Sil}}+\frac{1}{2} f \mathrm{O}_{2}-\frac{1}{2} f \mathrm{~S}_{2}-\ln a_{\mathrm{SO}^{2-}}^{\mathrm{Sil}}$ 

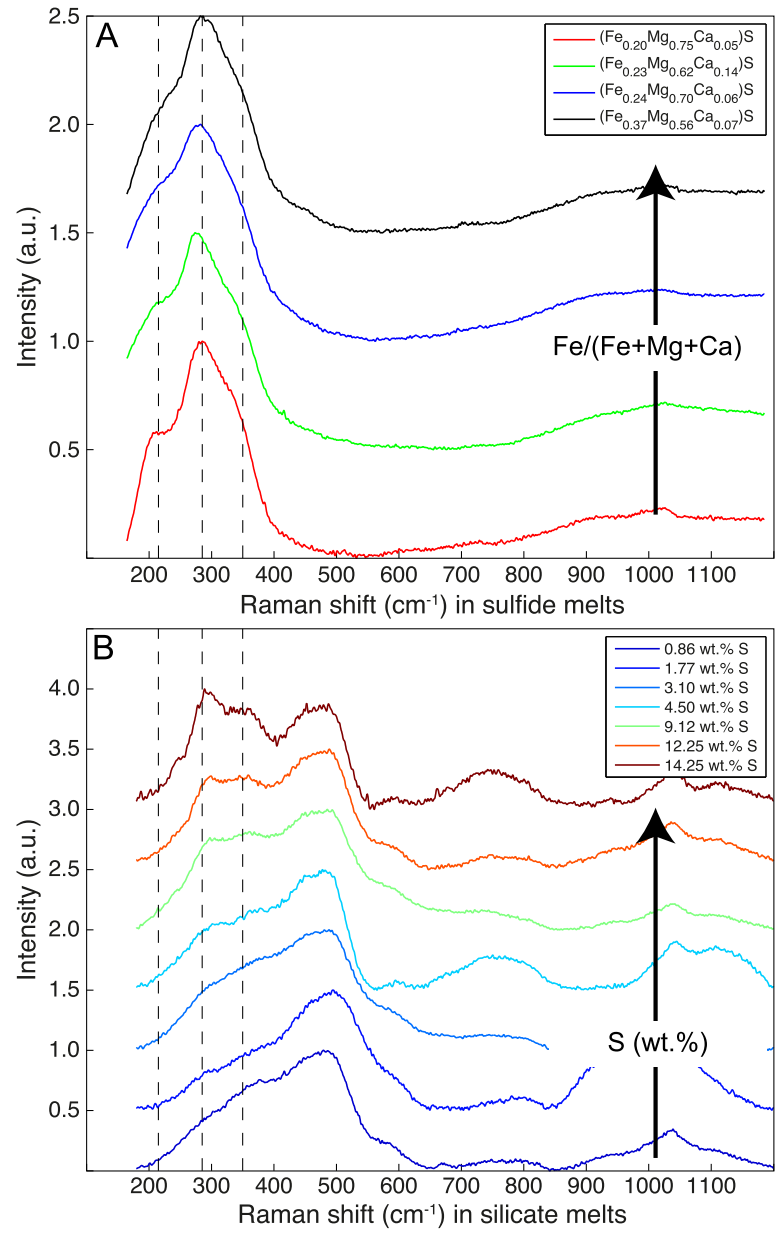

Fig. 4. A. Raman spectra of experimental (Mg,Ca,Fe)S metal melts. Spectra are colorcoded as a function of the $\mathrm{Fe} /(\mathrm{Mg}+\mathrm{Ca})$ ratio. Experiments were performed at temperatures between 1310 and $1560^{\circ} \mathrm{C}, 0.1 \mathrm{GPa}$ and $\mathrm{fO}_{2}$ conditions between IW-7.0 and IW-8.4. The vertical dashed lines show the position of Raman peaks observed and calculated in natural and synthetic MgS and CaS by Avril et al. (2013). B. Raman spectra of experimental quenched silicate melts. Spectra are color-coded as a function of the sulfur concentration of the melt (SCSS). Experiments were performed between 1200 and $1560^{\circ} \mathrm{C}, 0.1 \mathrm{GPa}$ and $\mathrm{fO}_{2}$ conditions between IW-3.6 and IW-8.4. Note the appearance of increasingly intense peaks at 285 and $350 \mathrm{~cm}^{-1}$ with increasing sulfur content in the melt. This suggests that sulfur $\left(\mathrm{S}^{2-}\right)$ forms complexes with $\mathrm{Mg}^{2+}$ and $\mathrm{Ca}^{2+}$ in the structure of the silicate melt (O'Neill and Mavrogenes, 2002). (For interpretation of the colors in this figure, the reader is referred to the web version of this article.)

where $a$ is the activity of $\mathrm{O}^{2-}$ or $\mathrm{S}^{2-}$. The abundance of $\mathrm{O}^{2-}$ anions in silicate melts is high and Eq. (4) can therefore be simplified as follows:

$\ln [\mathrm{S} w \mathrm{w} . \%]_{\mathrm{SCSS}}=\ln C_{\mathrm{S}}+\frac{1}{2} \ln \left(\frac{f \mathrm{O}_{2}}{f \mathrm{~S}_{2}}\right)$

where $S_{S C S S}$ is the sulfur content of the silicate melt at sulfide saturation and $C_{S}$ is a pseudoequilibrium constant (sulfide capacity) controlled by silicate liquid composition (Haughton et al., 1974; O'Neill and Mavrogenes, 2002):

$\ln C_{\mathrm{S}}=A_{\mathrm{o}}+\sum A_{i} X_{i}$

where $X$ is the mole fraction of cation $i$ and $A$ are regression coefficients. Combining Eq. (5) and Eq. (6) indicates that the sulfur content in the silicate melt at sulfide saturation (Eq. (5)) is a function of melt composition, $\mathrm{fO}_{2}$ and $\mathrm{fS}_{2}$, the last two parameters being partly controlled by pressure and temperature.

The equilibrium between a silicate melt and a sulfide phase (solid or liquid) can be described by:
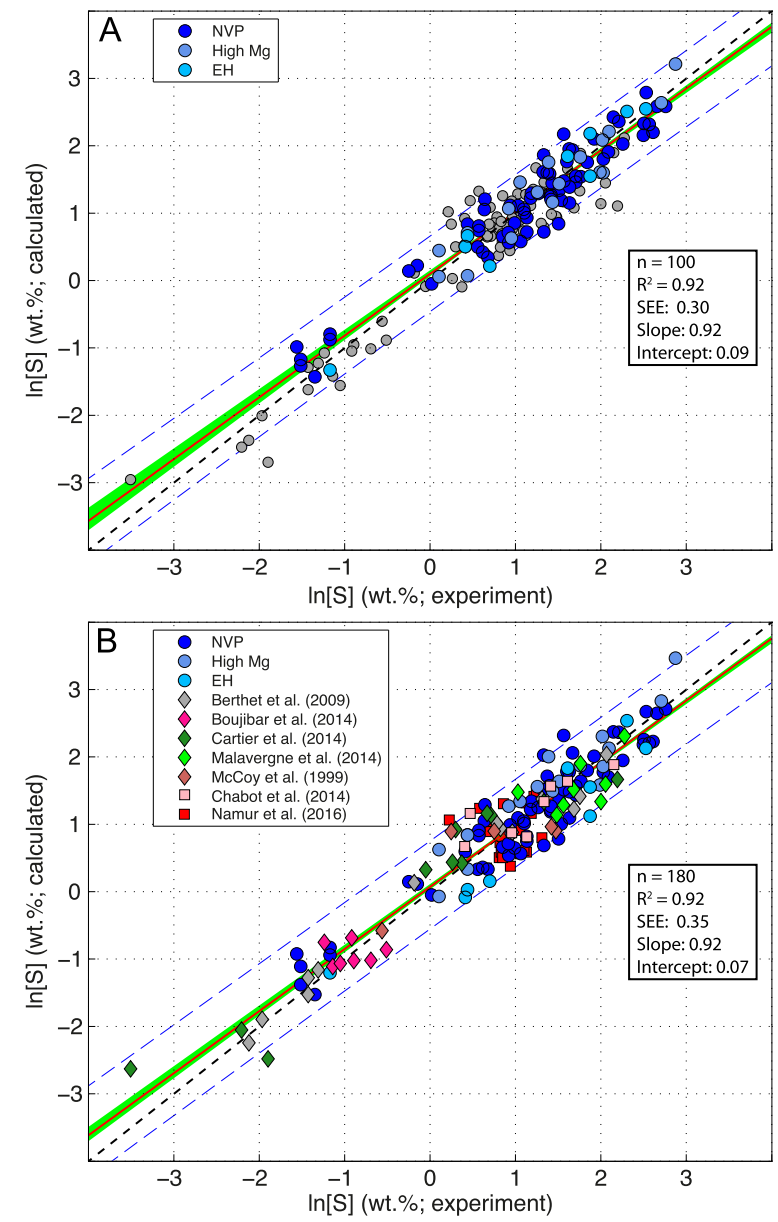

Fig. 5. Modeling of sulfur concentration at sulfide saturation in silicate melts. A. Calculated vs observed $\ln [S]_{S c s s}$. The model was calibrated using the experiments of this study (blue symbols) only. Grey symbols are literature data, not included in the calibration database, that are plotted to test the reliability of our expression. The black dashed line is the line of equality $(1: 1)$ while the red line shows the slope of the linear regression. Dashed blue lines show the $90 \%$ confidence interval. The green area represents the result of a Monte Carlo simulation showing the robustness of the fit when $1 \sigma$ standard errors on melt (silicate and metal) compositions, error on pressure and temperature are taken into account. The quality of the regression is given in the white box on the right side of the diagram. B. Same model calibrated using the experiments performed in this study and published experiments performed under similar experimental conditions. See coefficients in Table 2. $n=$ number of experiments, SEE = standard error of estimates. (For interpretation of the colors in this figure, the reader is referred to the web version of this article.)

$\mathrm{MO}^{\mathrm{Sil}}+\frac{1}{2} \mathrm{~S}_{2}=\mathrm{MS}^{\mathrm{Sul}}+\frac{1}{2} \mathrm{O}_{2}$

Our experiments contain a silicate melt in equilibrium with a sulfide melt, which is either FeS and/or ( $\mathrm{Fe}, \mathrm{Mg}, \mathrm{Ca}) \mathrm{S}$. The cation $\mathrm{M}$ in Eq. (7) can therefore be $\mathrm{Fe}, \mathrm{Ca}$ or $\mathrm{Mg}$. The equilibrium constant of Eq. (7) can be expressed as:

$\frac{-\Delta G^{0}(7)}{R T}=\ln a_{\mathrm{MS}}^{\mathrm{Sul}}-\ln a_{\mathrm{MO}}^{\mathrm{Sil}}+\frac{1}{2} \ln f \mathrm{O}_{2}-\frac{1}{2} \ln f \mathrm{~S}_{2}$

for which $\Delta G^{0}$ is the Gibbs free energy of reaction. Combining Eq. (5) and Eq. (8) allows calculating SCSS:

$\ln [\mathrm{S} w \mathrm{w} . \%]_{\mathrm{SCSS}}=\frac{-\Delta G^{0}(7)}{R T}+\ln C_{\mathrm{S}}+\ln a_{\mathrm{MS}}^{\mathrm{Sul}}-\ln a_{\mathrm{MO}}^{\mathrm{Sil}}$

Equation (9) cannot be readily applied to our experiments and to Mercurian magmas in general for several reasons: (1) the relationship between $C_{S}$ and melt composition (Eq. (6)) was only calibrated for simplified systems and FeO-rich terrestrial basalts 
Table 2

Coefficients of regression for SCSS parameterization (Eq. (10)).

\begin{tabular}{|c|c|c|c|c|c|}
\hline & Coefficients & $1 \sigma^{\mathrm{a}}$ & $p$ Values $^{b}$ & \multicolumn{2}{|c|}{$\begin{array}{l}\text { Statistical fit quality } \\
\text { parameters }\end{array}$} \\
\hline$a$ & 7.25 & 0.64 & $2 \times 10^{-22}$ & $r^{2}$ & 0.928 \\
\hline b & $-2.54 \times 10^{4}$ & 0.13 & $4 \times 10^{-48}$ & RMSE & 0.351 \\
\hline c & 0.04 & 0.005 & 0.08 & $F$ & 225 \\
\hline d & -0.551 & 0.020 & $2 \times 10^{-69}$ & $p$-value & $7 \times 10^{-79}$ \\
\hline $\mathrm{eTiO}_{2}$ & -62 & 14 & $4 \times 10^{-5}$ & $n$ & 180 \\
\hline $\mathrm{eMgO}$ & 0.426 & 0.13 & 0.03 & & \\
\hline $\mathrm{eNa}_{2} \mathrm{O}$ & 1.56 & 0.31 & $1 \times 10^{-5}$ & & \\
\hline
\end{tabular}

a Standard deviation of each coefficient.

b $p$ Values test the significance of each parameter. We only kept parameters which are significant at the $10 \%$ significance level.

c $r^{2}$ is the coefficient of determination. $F$ (test for a significant linear regression between the response variable and the predictor variables) and $p$-value indicate that the model is significant at the $5 \%$ significance level. $n$ is the number of observations.

(Haughton et al., 1974; O'Neill and Mavrogenes, 2002); (2) a robust application of Eq. (9) not only requires an accurate determination of silicate melt compositions but also expressions accounting for the evolution of the activity coefficients $(\gamma)$ of divalent cations under highly reducing conditions. There is currently not enough information to predict the effect of melt composition and $\mathrm{fO}_{2}$ on these coefficients (O'Neill and Eggins, 2002; Toplis, 2005); (3) Eq. (9) requires an independent knowledge of the composition of sulfide melts $\left(\ln a_{\mathrm{MS}}^{\mathrm{Sul}}\right)$ in equilibrium with the magma. Mercurian basalts show a correlation between S, Ca and $\mathrm{Mg}$, possibly indicating the presence of $(\mathrm{Mg}, \mathrm{Ca}, \mathrm{Fe}) \mathrm{S}$ sulfide melts (Malavergne et al., 2014) for which activities of the various components cannot be calculated.

Given the impossibility of using Eq. (9) to model the behavior of sulfur in Mercurian magmas, we developed a new thermodynamically inspired empirical model to predict SCSS in FeO-poor magmas (Fig. 5). We used an equation with a form similar to that of recent models of SCSS (Li and Ripley, 2005; Righter et al., 2009; Ding et al., 2015). We replaced the Gibbs free energy term of Eq. (9) by two terms taking into account pressure and temperature. The $C_{S}$ term is replaced by several terms accounting for liquid composition. For these compositional terms, we used molar fractions normalized to $\mathrm{SiO}_{2}$. This takes into account the degree of polymerization of the melt, which plays a role on SCSS (Holzheid and Grove, 2002), and also reduces the errors when applying the model to Mercurian magmas for which elemental ratios (normalized to $\mathrm{Si}$ ) were measured by MESSENGER. In theory, SCSS could be adequately modeled independently of $\mathrm{fO}_{2}$ because $\mathrm{S}$ in both the silicate melt and the sulfide melt is present as $S^{2-}$. In that case, SCSS is controlled by the $\mathrm{FeO}$ content of the silicate melt (Wykes et al., 2015) and sulfide saturation is not a redox reaction. However in a reduced system, estimating SCSS requires an accurate estimate of the melt $\mathrm{FeO}$ content and the activity coefficients at very low FeO concentrations (O'Neill and Mavrogenes, 2002; Gaillard and Scaillet, 2009; Wykes et al., 2015), which is problematic. We therefore replaced the term $\ln a_{\mathrm{FeO}}^{\mathrm{Sil}}$ (Eq. (9)) by $\log f \mathrm{O}_{2}$, which controls the $\mathrm{FeO}$ content of a silicate melt in equilibrium with metallic melt (Gaillard et al., 2013; Zolotov et al., 2013) and exerts a major control on SCSS (Wykes et al., 2015). For our experiments which contain a metal phase in which sulfur dissolves as $\mathrm{S}^{0}$, the use of a $\mathrm{fO}_{2}$ term is appropriate. However, care must be taken when applying this model to natural, magmatic systems which may not contain a metal phase. By stepwise multiple-linear regression, we obtained the following expression for SCSS:

$\ln [\mathrm{S} w \mathrm{w} . \%]_{\mathrm{SCSS}}=a+\frac{b}{T}+\frac{c P}{T}+d \log \mathrm{fO}_{2}+\sum e_{i} \frac{X_{i}}{X_{\mathrm{SiO}_{2}}}$

where $S$ is the sulfur content at sulfide saturation, $T$ is temperature (K), $P$ is pressure (bar), $f \mathrm{O}_{2}$ is the oxygen fugacity (bar) and
$X_{i}$ are the mole fractions of oxides in the melt recalculated to a total of $100 \%$ on a sulfur-free basis. We ran several statistical tests and only kept statistically significant terms $\left(X_{i}\right)$ in the regression. Coefficients of regression and details on uncertainties are described in Table 2 and the results of the regression are shown in Fig. 5. The individual effects of pressure, temperature, $\mathrm{fO}_{2}$ and melt compositions cannot be easily determined from Eq. (10) because these parameters are strongly correlated. However, it appears that $\mathrm{fO}_{2}$ and temperature exert the main control on SCSS. We also calculate a minor positive effect of pressure on SCSS. This is in agreement with previous experimental studies (Malavergne et al., 2014) and confirms that the effect of temperature on SCSS is slightly dependent on pressure (Vander Kaaden and McCubbin, 2015a).

\section{Discussion}

Our experiments and new parameterization of SCSS allow us to track the behavior of sulfur during the magmatic history of Mercury. Assuming that Mercury differentiated through the formation of a magma ocean (Brown and Elkins-Tanton, 2009; Charlier et al. 2013; Chabot et al., 2014), early differentiation of the planet did set the sulfur content of the core and the lherzolitic mantle. Partial melting of the mantle then produced the secondary crust (Weider et al., 2015; Namur et al., 2016). In the following, we discuss the mechanism of sulfur migration from the Mercurian mantle to the crust. We then consider that the oxygen fugacity conditions during accretion and differentiation of the planet did set the $\mathrm{FeO}$ content of the mantle during mantle-core equilibration. We therefore used the sulfur content of Mercurian lavas together with our expression of SCSS (Eq. (10)) to calculate the oxygen fugacity conditions of their mantle source regions. The use of Eq. (10) is appropriate because some surface melts were produced at the mantle-core interface indicating that the mantle source was metal saturated (Namur et al., 2016) and Mercurian lavas contain some Fe, possibly included in Fe-silicides (Weider et al., 2014). We finally discuss the likely distribution of sulfur between the core and mantle on Mercury.

\subsection{Transport of sulfur from the mantle to the Mercurian surface}

An important question about Mercurian lavas concerns the origin of their high sulfur concentrations. Our experiments suggest that they could simply be explained by high SCSS under reducing conditions. However, they could also result from accumulation of sulfides transported as sulfide globules during flow of silicate melt from the mantle to the surface of the planet (Malavergne et al., 2014). During mantle melting on Earth, it is commonly assumed that sulfide melts (FeS) stay in the mantle restite. This is partly because they form isolated droplets at four-grain junctions (Holzheid et al., 2000) but also because of the large density contrast between silicate melts $\left(2.75 \mathrm{~g} / \mathrm{cm}^{3}\right.$; Sparks et al., 1980), mantle rocks $\left(3.5 \mathrm{~g} / \mathrm{cm}^{3}\right.$; Shorttle et al., 2014) and FeS melts $\left(4.5 \mathrm{~g} / \mathrm{cm}^{3}\right.$; Mungall and Su, 2005). Most of the experiments presented in this study show equilibrium between a silicate melt and an immiscible sulfide melt dominated by FeS. However, in our most reducing experiments, the sulfide melt contains a significant proportion of $\mathrm{Mg}$, $\mathrm{Ca}$ as well as a variable proportion of Fe (Fig. 3b). This is important for the magmatic history of Mercury because of the small density contrast between $(\mathrm{Mg}, \mathrm{Ca}) \mathrm{S}$ melts $\left(2.6 \mathrm{~g} / \mathrm{cm}^{3}\right)$, the mantle rocks $\left(3.0-3.2 \mathrm{~g} / \mathrm{cm}^{3}\right.$; Supplementary Fig. S3; Hauck et al., 2013) and the primary mantle-derived silicate melts $\left(<2.7 \mathrm{~g} / \mathrm{cm}^{3}\right.$; Supplementary Fig. S3; Vander Kaaden and McCubbin, 2015b). However, even for such a low density contrast the capillary pressure imposed by reducing the radius of curvature of a sulfide droplet $\left(10^{4} \mathrm{~Pa}\right)$ still strongly exceeds the buoyancy 
force for sulfide melt migration $(<10 \mathrm{~Pa}$; calculated using Mercurian gravity; Mungall and Su, 2005) in a typical lherzolite. This makes segregation of sulfide droplets quantitatively impossible. With increasing degree of mantle melting, the capillary pressure decreases and sulfide melt droplets eventually become mobile. This however requires a degree of melting exceeding 40 vol.\% (Holzheid et al., 2000), which is higher than the melt fraction needed to produce the S-rich lavas from NVP, SP and IcP-HCT (Namur et al., 2016). In addition, coalescence of sulfide droplets through Ostwald ripening would require extremely low abundances of sulfides and a mantle with unrealistically large ( $\mathrm{cm}$-scale) crystals before sulfide melts become effectively mobile (Mungall and Su, 2005).

Our calculations and physical arguments presented above therefore suggest that Mercurian lavas did not carry sulfide melts or sulfide minerals during their ascent from the mantle source regions to the surface of the planet. This implies that their high sulfur content is related to high sulfur solubility in the mafic magma, which probably explains the absence of spectral evidence for a sulfide phase at the Mercurian surface (McClintock et al., 2008; Izenberg et al., 2014).

\subsection{Oxygen fugacity conditions during mantle melting and basaltic eruptions}

It was suggested that Mercurian lavas were in equilibrium with a sulfide-bearing lherzolite when they left their mantle source regions (Zolotov et al., 2013; Malavergne et al., 2014). This implies that sulfide minerals were not entirely exhausted during the par-
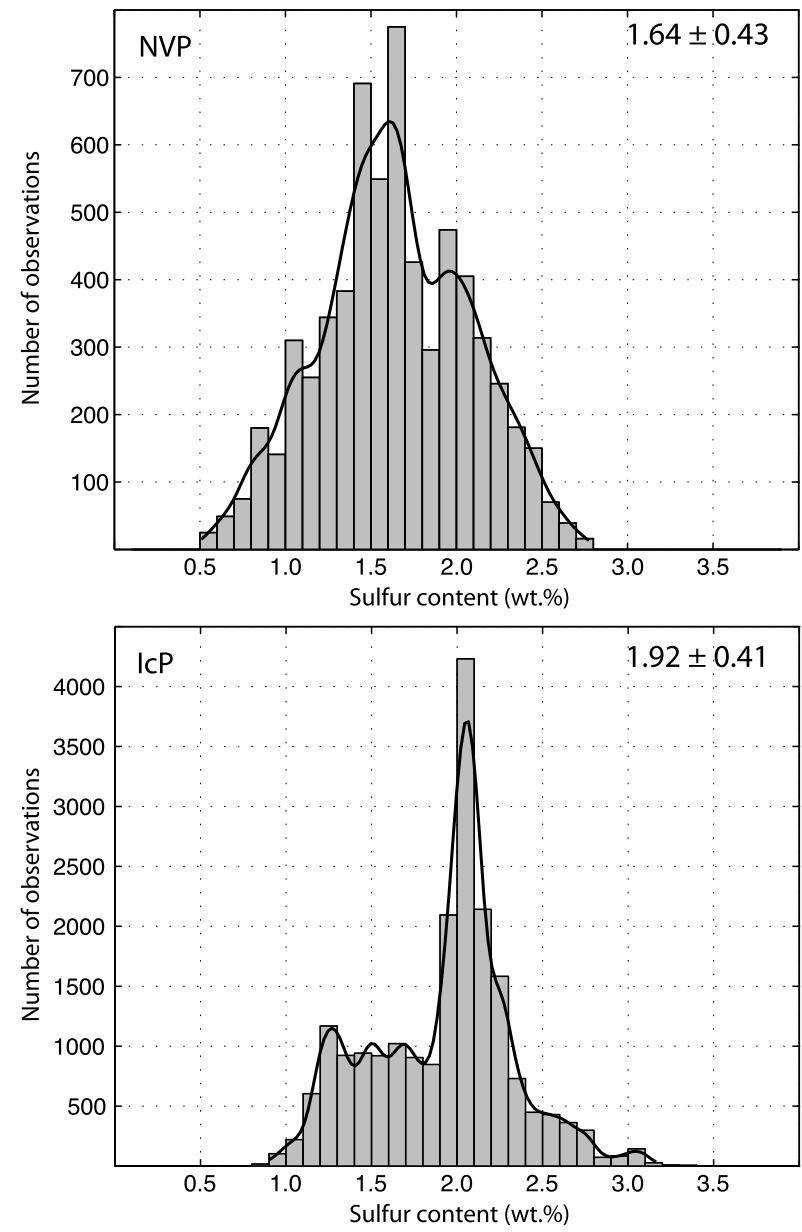

tial melting process. This is in qualitative agreement with chemical data from MESSENGER (Weider et al., 2015) which show that rocks from the $\mathrm{HMg}$ terrane, which require the highest degree of mantle melting $(>40 \%)$, are not depleted in sulfur compared to lavas from IcP-HCT ( $<35 \%$ of melting), SP and NVP ( $<30 \%$ of melting; Namur et al., 2016; Vander Kaaden and McCubbin, 2016). It is therefore reasonable to assume that Mercurian lavas were still at sulfide saturation when they erupted at the surface of the planet. Their sulfur content can be used to estimate the redox conditions of their mantle source regions using Eq. (10) assuming that the mantle contain a metal phase (Weider et al., 2015). Even in the absence of metal in the Mercurian mantle, this treatment is valid because the $\mathrm{fO}_{2}$ conditions during mantle-core equilibration did set the low $\mathrm{FeO}$ content of the mantle and therefore the high SCSS in mantle melts (Gaillard and Scaillet, 2009; Wykes et al., 2015).

We calculated the compositions of Mercurian surface magmas using the most recent maps produced from MESSENGER XRS data (Weider et al., 2015). We focused on the northern hemisphere for which the spatial resolution of MESSENGER measurements is the highest. We combined individual maps of $\mathrm{Mg} / \mathrm{Si}, \mathrm{Ca} / \mathrm{Si}, \mathrm{Al} / \mathrm{Si}$ and $\mathrm{S} / \mathrm{Si}$ and only worked on pixels for which those 4 ratios were measured (Supplementary Fig. S4). This method allows investigating only some parts of the northern hemisphere because the $\mathrm{Ca} / \mathrm{Si}$ and $\mathrm{S} / \mathrm{Si}$ maps are incomplete. We produced $>49000$ groups of 4 pixels $\left(0.5^{\circ}\right.$ latitude $\times 0.5^{\circ}$ longitude $)$ that we converted to chemical compositions $\left(\mathrm{SiO}_{2}, \mathrm{Al}_{2} \mathrm{O}_{3}, \mathrm{MgO}, \mathrm{CaO}\right.$ and $\left.\mathrm{S}\right)$. Each pixel group was assigned to a geochemical terrane (NVP, SP, IcP-HCT and HMg;
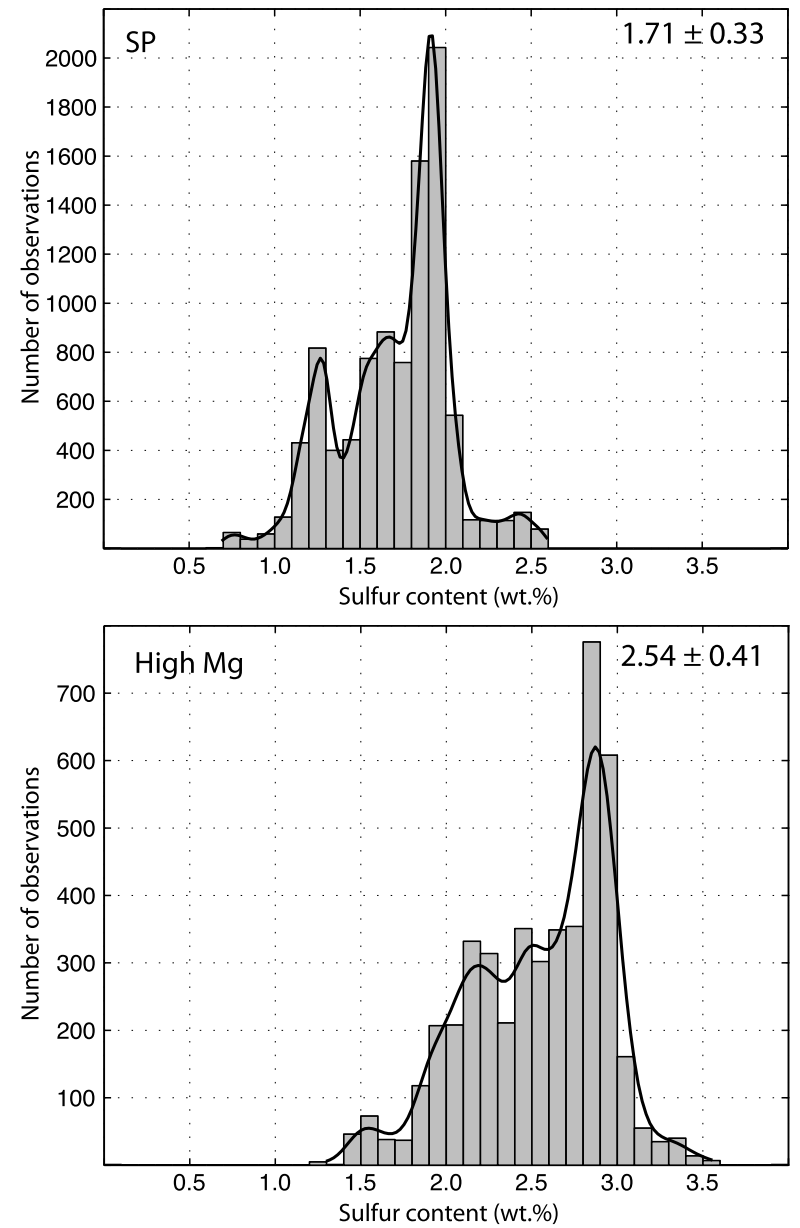

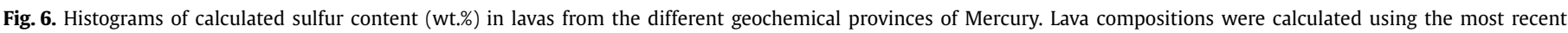

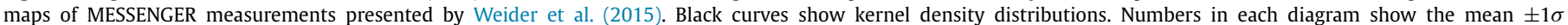
standard deviation. 


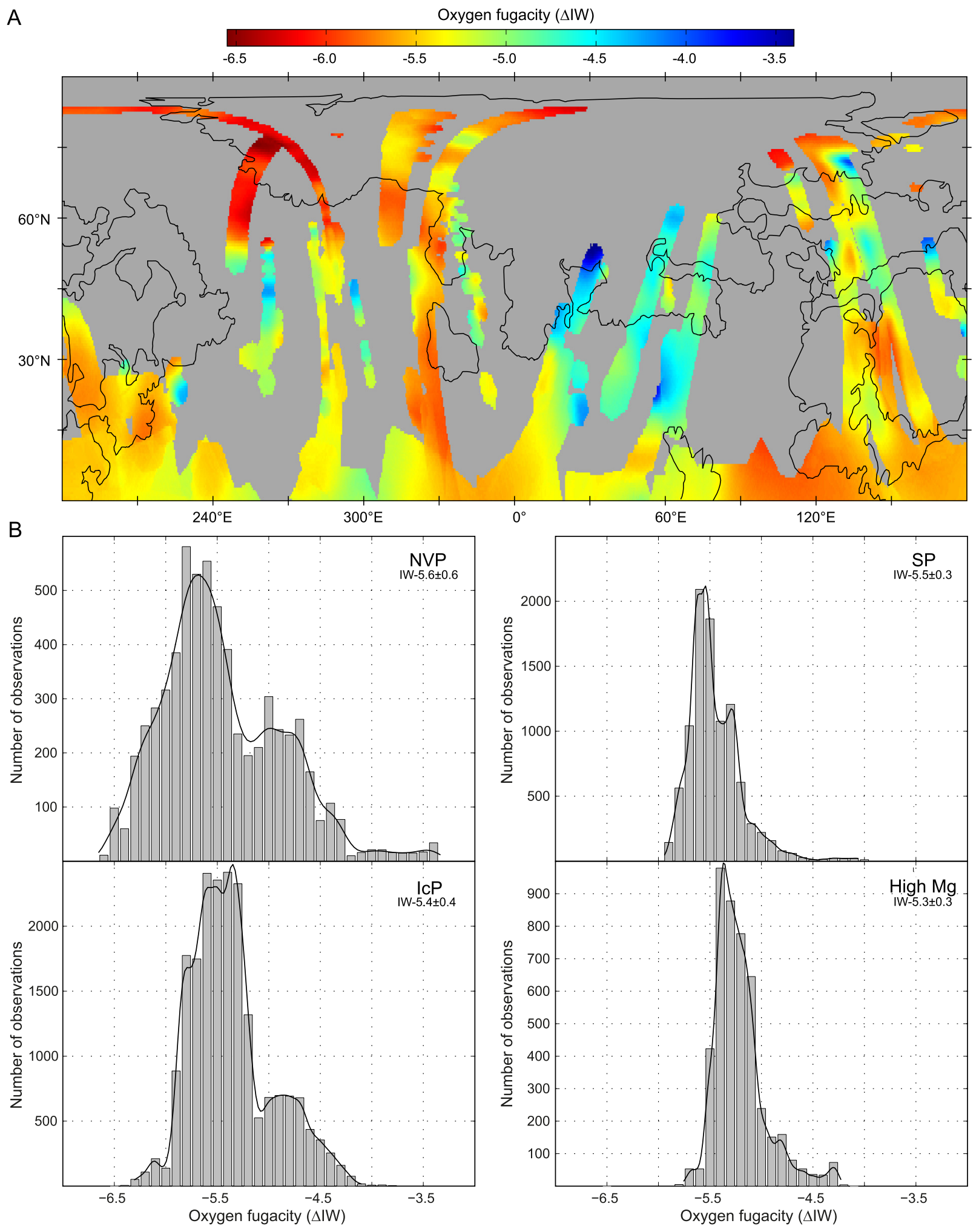

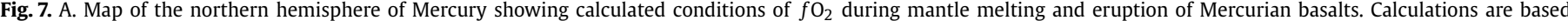

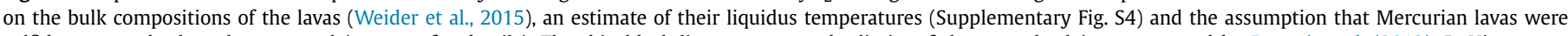

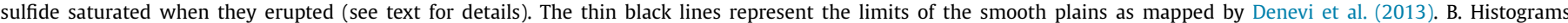

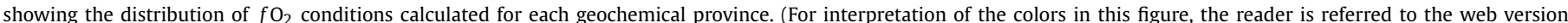
of this article.) 

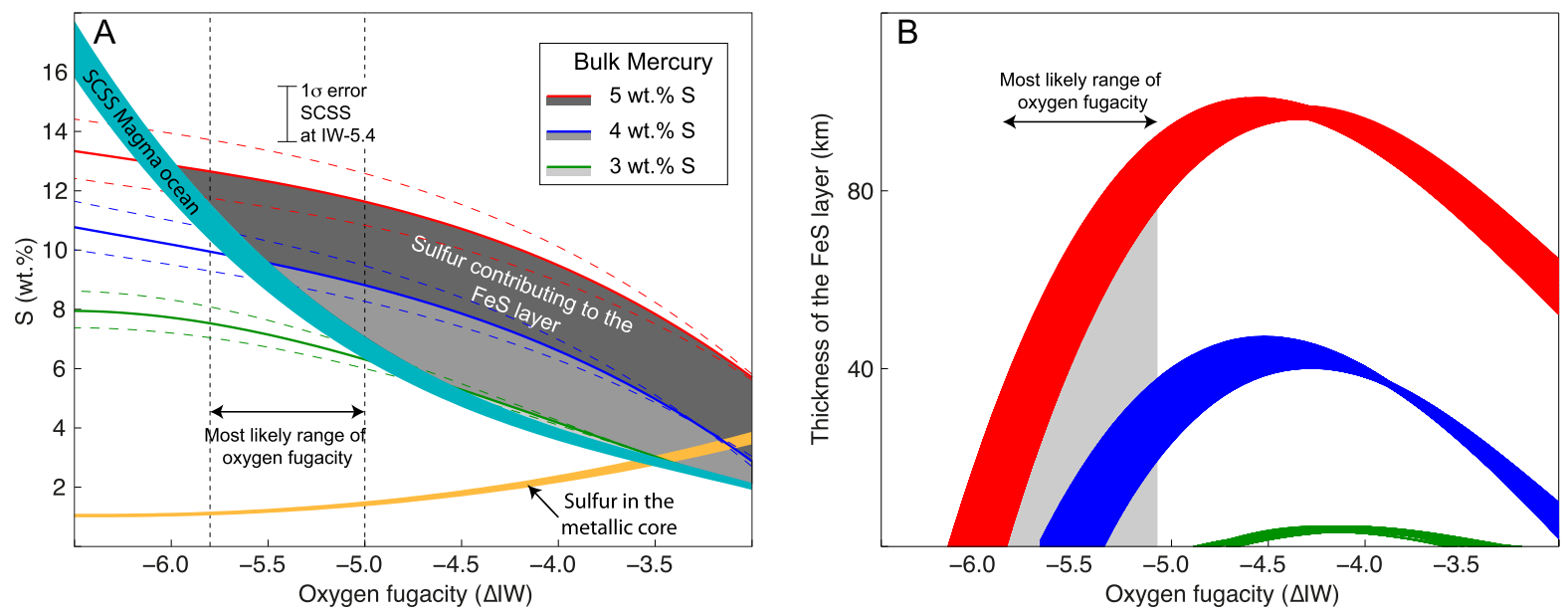

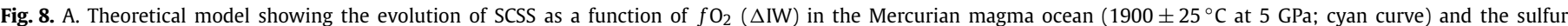

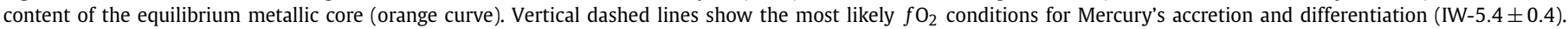

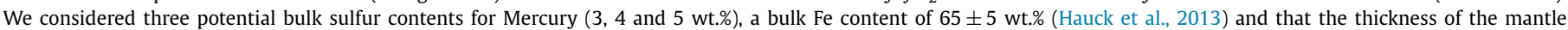

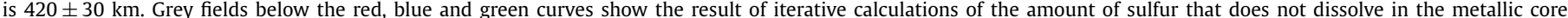

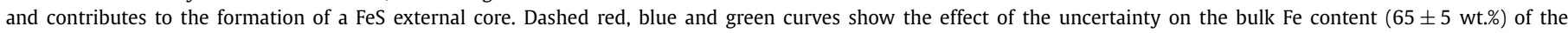

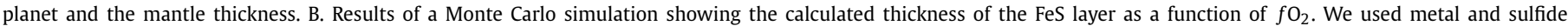

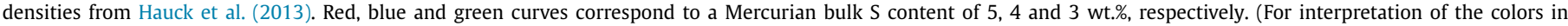
this figure, the reader is referred to the web version of this article.)

Peplowski et al., 2015). We considered that NVP lavas have high $\mathrm{Na}_{2} \mathrm{O}$ contents (Na/Si: 0.20; $\sim 7$ wt.\% $\mathrm{Na}_{2} \mathrm{O}$ ), SP lavas have intermediate $\mathrm{Na}_{2} \mathrm{O}$ contents $\left(\mathrm{Na} / \mathrm{Si}: 0.14 ; \sim 5\right.$ wt.\% $\left.\mathrm{Na}_{2} \mathrm{O}\right)$ and IcP-HCT and $\mathrm{HMg}$ lavas have lower $\mathrm{Na}_{2} \mathrm{O}$ contents ( $\mathrm{Na} / \mathrm{Si}: 0.06$; 2 wt.\% $\mathrm{Na}_{2} \mathrm{O}$; Peplowski et al., 2014). The calculated sulfur content of Mercurian basalts is variable but generally high. It averages $2.54 \pm 0.41 \mathrm{wt} . \%$ in the High $\mathrm{Mg}$ terrane and $1.92 \pm 0.41 \mathrm{wt}$.\% in IcP-HCT lavas, but is lower in SP $(1.71 \pm 0.33$ wt.\%) and NVP (1.64 \pm 0.43 wt.\%) lavas (Fig. 6).

For each pixel group, we calculated a volatile-free composition (Supplementary Fig. S4) and estimated the 1-bar liquidus temperature of each magma (Supplementary Fig. S5). We then iteratively estimated SCSS for $f_{2}$ conditions between IW and IW-8. Results were finally compared to the actual sulfur content of each composition to extract the $\mathrm{fO}_{2}$ conditions during eruption of these basalts (Fig. 7). We estimate that Mercurian magmas were produced at $f \mathrm{O}_{2}$ conditions ranging from IW-3.4 to IW-6.6 (error map in Supplementary Fig. S6). This range is relatively similar to that obtained based on the Fe-content of Mercurian basalts (McCubbin et al., 2012) but our new data show that a large majority of Mercurian magmas were produced in a more restricted range of $f \mathrm{O}_{2}$ conditions (IW-5.4 \pm 0.4 ). The average $\mathrm{fO}_{2}$ is furthermore relatively similar for the various geochemical provinces of Mercury. Nevertheless, lavas from the NVP show a relatively large variability of $\mathrm{fO}_{2}$. The region between $180-290^{\circ} \mathrm{E}$ and $50-85^{\circ} \mathrm{N}$ shows the most reducing conditions of the northern hemisphere, while the region between $15-70^{\circ} \mathrm{E}$ and $40-55^{\circ} \mathrm{N}$ shows the most oxidizing conditions. Although this could be explained by melting mantle source regions which are heterogeneous in terms of intrinsic $\mathrm{fO}_{2}$ conditions, other explanations cannot be ruled out: (1) highly reducing conditions could be an artifact due to high $S$ concentrations originating from thermal migration of sulfur from the equator to the poles of Mercury (Sprague et al., 1995); (2) the oxidizing conditions could also be an artifact due to low $\mathrm{S}$ concentrations originating from $\mathrm{S}$ volatilization during impacts (Nittler et al., 2001; Arai et al., 2008), sulfur degassing during volcanic eruptions (Righter et al., 2009; Nittler et al., 2014; Weider et al., 2016) or sulfur loss during thermal decomposition of sulfide phases (Helbert et al., 2013; Blewett et al., 2013). However, we note that these regions with less sulfur do not show a higher than average crater density (Weider et al., 2015) and sulfur degassing at reducing conditions is minimal because sulfur is more stable in the melt phase than in the gas (Gaillard and Scaillet, 2009).

\subsection{Sulfur content of the mantle and the core}

Our new constraints on oxygen fugacity in Mercury's interior can be used to estimate the bulk sulfur content of the Mercurian primordial mantle and the core. We made the assumption that Mercury formed by accretion of metal-rich chondritic building blocks (enstatite chondrites and/or bencubbinite chondrites; Malavergne et al., 2010, 2014; Zolotov et al., 2013). We used average sulfide modes (10.0 \pm 2.50 wt.\%; Jarosewich, 1990; Javoy et al., 2010 ) and compositions ( FeS with $37.0 \pm 1.5$ wt.\% S; Javoy et al., 2010 ) in EH and CB meteorites and calculated that Mercury may contain 2.7-4.6 wt.\% S with the highest probability lying in the range of $3.8 \pm 0.5$ wt.\% S. The exact nature of Mercurian building blocks is however unimportant for the following discussion because all chondritic materials have high $S$ content $(\sim 2-5$ wt.\% S; Fig. 1). We considered that the bulk Fe content of the planet (mostly in the core) is $65 \pm 5$ wt.\% (Hauck et al., 2013) and that the mantle is $420 \pm 30 \mathrm{~km}$ thick (mantle-core boundary at $5 \mathrm{GPa}$; Padovan et al., 2015). We used a single-stage core formation model (Rubie et al., 2003; Walter and Cottrell, 2013) in which the sulfur content of the various reservoirs is set by metal-silicate equilibration at the bottom of the magma ocean (Corgne et al., 2009; Chabot et al., 2014). We estimated that the liquidus temperature of the S-free magma ocean was $1900 \pm 25^{\circ} \mathrm{C}$ at $5 \mathrm{GPa}$ (Namur et al., 2016). Using Eq. (10), we calculated the maximum sulfur content that can be dissolved in the silicate magma ocean (SCSS) and iteratively recalculated the liquidus temperature by considering a liquidus depression of $10^{\circ} \mathrm{C} / \mathrm{wt} . \% \mathrm{~S}$ (Namur et al., 2016). We also used the experimental database from Boujibar et al. (2014) and metal melt compositions in experiments at $5 \mathrm{GPa}$ from Cartier et al. (2014a) to estimate $D_{\mathrm{S}}^{\mathrm{Met} / \mathrm{Sil}}(0.05-2.90)$ for the $\mathrm{fO}_{2}$ range of Mercury's interior. These values are in agreement with those reported by Gaillard et al. (2013).

Within the possible range of $\mathrm{fO}_{2}$ for Mercury's interior (IW-3.5 to IW-6.5; Fig. 7), the primordial Mercurian mantle may have contained 2-12 wt.\% S (Fig. 8a). However, results from Fig. 7 show that Mercury probably differentiated at IW-5.4 \pm 0.4 . Within this 
more restricted $f_{2}$ range, the sulfur content of the Mercurian mantle must be between 7 and 11 wt.\%. For a bulk sulfur concentration of $\sim 4 \mathrm{wt} . \%$ for the planet, the primordial mantle would contain 8-9 wt.\% S. For most of the $f_{2} \mathrm{O}_{2}$ conditions investigated in Fig. 8a, a significant amount of sulfur cannot be dissolved in the silicate magma ocean or in the equilibrium metallic core. Given the presence of an immiscibility field in the Fe-Si-S system at low pressure ( $<15 \mathrm{GPa}$; Morard and Katsura, 2010), we considered that the excess sulfur formed an immiscible FeS melt at the mantlecore boundary. The presence of a $200 \mathrm{~km}$-thick solid FeS layer has been initially proposed by Smith et al. (2012) to account for the moment of inertia parameters of Mercury. This interpretation has been revisited by Hauck et al. (2013) who suggested that such a solid layer is not required to explain the geophysical properties of Mercury. However, experimental constraints (Chabot et al., 2014; Malavergne et al., 2014) indicate that sulfur not dissolving into the metallic core or the silicate mantle will form a FeS layer at the mantle-core interface. We calculate that the thickness of this sulfide layer is likely to be smaller than $90 \mathrm{~km}$ (Fig. 8b) or even lower than $40 \mathrm{~km}$ if Mercury's bulk $\mathrm{S}$ content is $\sim 4 \mathrm{wt} . \%$. Our approach however does not bring any constraint on the present physical state (solid or liquid) of the FeS layer. Future investigations of the physical properties of Mercury using results from MESSENGER and BepiColombo will be useful to refine our new calculations on core structure and composition.

\section{Conclusions}

Our new experiments on compositions relevant to Mercury allow us to draw a few key conclusions:

1. Under reducing conditions, sulfur dissolves as $\mathrm{S}^{2-}$ in the silicate melt and forms complexes with $\mathrm{Fe}^{2+}, \mathrm{Ca}^{2+}$ and $\mathrm{Mg}^{2+}$. The sulfur concentration at sulfide saturation (SCSS) in the silicate melts strongly increases with reducing conditions and increasing temperature.

2. The composition of a sulfide melt in equilibrium with the silicate melt is dominated by a FeS component at $f \mathrm{O}_{2}$ conditions from IW to IW-6. At more reducing conditions ( $<$ IW-6), under which the $\mathrm{FeO}$ content of the silicate melts approaches 0 , the equilibrium sulfide melt is dominated by $(\mathrm{Mg}, \mathrm{Ca}, \mathrm{Fe}) \mathrm{S}, \pm \mathrm{FeS}$.

3. A new parameterization of SCSS in silicate melts relevant to Mercurian magmas is proposed. SCSS can be adequately modeled with an expression taking into account temperature and oxygen fugacity, which controls the melt $\mathrm{FeO}$ content.

We applied our experimental results to constrain the distribution of $S$ in the different reservoirs of Mercury and to decipher the oxygen fugacity of the Mercurian mantle. We suggest that the $S$ concentrations observed at the surface of Mercury were transported as dissolved $S^{2-}$ in silicate melts. We also estimated that Mercurian lavas were produced in mantle source regions having intrinsic oxygen fugacity conditions ranging from IW-3.5 to IW-6.5. However, a large majority of the chemical compositions (>75\%) can be explained by a much narrower range of oxygen fugacity (IW-5.4 \pm 0.4 ). Using these new constraints, we calculated that the primordial mantle of Mercury probably contains 7 to $11 \mathrm{wt} . \% \mathrm{~S}$ and that the core is layered. We suggest that it is made up of a large $\mathrm{S}$-poor $(\sim 1 \mathrm{wt} . \% \mathrm{~S})$ internal metallic $(\mathrm{FeSi})$ core surrounded by a thin $(<90 \mathrm{~km})$ FeS layer.

\section{Acknowledgements}

ON acknowledges support from the von Humboldt Foundation and from a Marie Curie Intra-European Fellowship (SULFURONMERCURY - 327046). ON also acknowledges support from the DFG
Core Facility for High-Pressure Research from the German Science Foundation (KE 501/10-1) for the high-pressure experiments (BGI). BC was supported by the von Humboldt Foundation, a BELSPO Grant, and the BRAIN-be program (BR/143/A2/COME-IN). A.M. Welsch is thanked for her help with Raman spectroscopy and D. Lattard for sharing her expertise with evacuated silica tubes. We appreciate comments from C. Sotin (editor), F. Gaillard and an anonymous reviewer that significantly improved the quality of the paper.

\section{Appendix A. Supplementary material}

Supplementary material related to this article can be found online at http://dx.doi.org/10.1016/j.epsl.2016.05.024.

\section{References}

Arai, T., Okada, T., Yamamoto, Y., Ogawa, K., Shirai, K., Kato, M., 2008. Sulfur abundance of asteroid 25143 Itokawa observed by X-ray fluorescence spectrometer onboard Hayabusa. Earth Planets Space 60, 21-31.

Avril, C., Malavergne, V., Caracas, R., Zanda, B., Reynard, B., Charon, E., Bobocioiu, E. Brunet, F., Borensztajn, S., Pont, S., Tarrida, M., Guyot, F., 2013. Raman spectroscopic properties and Raman identification of CaS-MgS-MnS-FeS- $\mathrm{Cr}_{2} \mathrm{FeS}_{4}$ sulfides in meteorites and reduced sulfur-rich systems. Meteorit. Planet. Sci. 48, 1415-1426.

Berthet, S., Malavergne, V., Righter, K., 2009. Melting of the Indarch meteorite (EH4 chondrite) at $1 \mathrm{GPa}$ and variable oxygen fugacity: implications for early planetary differentiation processes. Geochim. Cosmochim. Acta 73, 6402-6420.

Blewett, D.T., Vaughan, W.M., Xiao, Z., Chabot, N.L., Denevi, B.W., Ernst, C.M., Helbert, J., D’Amore, M., Maturilli, A., Head, J.W., Solomon, S.C., 2013. Mercury's hollows: constraints on formation and composition from analysis of geological setting and spectral reflectance. J. Geophys. Res., Planets 118, 1013-1032.

Boujibar, A., Andrault, D., Bouhifd, M.A., Bolfan-Casanova, N., Devidal, J.-L., Trcera, N., 2014. Metal-silicate partitioning of sulphur, new experimental and thermodynamic constraints on planetary accretion. Earth Planet. Sci. Lett. 391, 42-54.

Brown, S.M., Elkins-Tanton, L.T., 2009. Compositions of Mercury's earliest crust from magma ocean models. Earth Planet. Sci. Lett. 286, 446-455.

Byrne, P.K., Klimczak, C., Williams, D.A., Hurwitz, D.M., Solomon, S.C., Head, J.W., Preusker, F., Oberst, J., 2013. An assemblage of lava flow features on Mercury. J. Geophys. Res., Planets 118, 1303-1322.

Cartier, C., Hammouda, T., Doucelance, R., Boyet, M., Devidal, J.-L., Moine, B., 2014a. Experimental study of trace element partitioning between enstatite and melt in enstatite chondrites at low oxygen fugacities and 5 GPa. Geochim. Cosmochim. Acta 130, 167-187.

Cartier, C., Hammouda, T., Boyet, M., Bouhifd, M.A., Devidal, J.-L., 2014b. Redox control of the fractionation of niobium and tantalum during planetary accretion and core formation. Nat. Geosci. 7, 573-576.

Chabot, N.L., Wollack, E.A., Klima, R.L., Minitti, M.E., 2014. Experimental constraints on Mercury's core composition. Earth Planet. Sci. Lett. 390, 199-208.

Charlier, B., Grove, T.L., Zuber, M.T., 2013. Phase equilibria of ultramafic compositions on Mercury and the origin of the compositional dichotomy. Earth Planet. Sci. Lett. 363, 50-60.

Corgne, A., Siebert, J., Badro, J., 2009. Oxygen as a light element: a solution to singlestage core formation. Earth Planet. Sci. Lett. 288, 108-114.

Denevi, B.W., Ernst, C.M., Meyer, H.M., Robinson, M.S., Murchie, S.L., Whitten, J.L., Head, J.W., Watters, T.R., Solomon, S.C., Ostrach, L.R., Chapman, C.R., Byrne, P.K., Klimczak, C., Peplowski, P.N., 2013. The distribution and origin of smooth plains on Mercury. J. Geophys. Res., Planets 118, 891-907.

Ding, S., Dasgupta, R., Tsuno, K., 2014. Sulfur concentration of Martian basalts at sulfide saturation at high pressures and temperatures: implications for deep sulfur cycle on Mars. Geochim. Cosmochim. Acta 131, 227-246.

Ding, S., Dasgupta, R., Lee, C.-T.A., Wadhwa, M., 2015. New bulk sulfur measurements of Martian meteorites and modeling the fate of sulfur during melting and crystallization: implications for sulfur transfer from Martian mantle to crustatmosphere system. Earth Planet. Sci. Lett. 409, 157-167.

Ertel, W., Walter, M.J., Drake, M.J., Sylvester, P.J., 2006. Experimental study of platinum solubility in silicate melt to $14 \mathrm{GPa}$ and $2273 \mathrm{~K}$ : implications for accretion and core formation in Earth. Geochim. Cosmochim. Acta 70, 2591-2602.

Fogel, R.A., 2005. Aubrite basalt vitrophyres: the missing basaltic component and high sulfur silicate melts. Geochim. Cosmochim. Acta 69, 1633-1648.

Gaillard, F., Scaillet, B., 2009. The sulfur content of volcanic gases on Mars. Earth Planet. Sci. Lett. 279, 34-43.

Gaillard, F., Michalski, J., Berger, G., McLennan, S.M., Scaillet, B., 2013. Geochemica reservoirs and timing of sulfur cycling on Mars. Space Sci. Rev. 174, 251-300.

Hauck, S.A., Margot, J.L., Solomon, S.C., Phillips, R.J., Johnson, C.L., Lemoine, F.G., Mazarico, E., McCoy, T.J., Padovan, S., Peale, S.J., Perry, M.E., Smith, D.E., Zuber, M.T., 2013. The curious case of Mercury's internal structure. J. Geophys. Res., Planets 118, 1204-1220 
Haughton, D.R., Roeder, P.L., Skinner, B.J., 1974. Solubility of sulfur in mafic magmas. Econ. Geol. 69, 451-467.

Helbert, J., Maturilli, A., D Amore, M., 2013. Visible and near-infrared reflectance spectra of thermally processed synthetic sulfides as a potential analog for the hollow forming materials on Mercury. Earth Planet. Sci. Lett. 369-370, 233-238.

Holzheid, A., Grove, T.L., 2002. Sulfur saturation limits in silicate melts and their implications for core formation scenarios for terrestrial planets. Am. Mineral. 87, 227-237.

Holzheid, A., Schmitz, M.D., Grove, T.L., 2000. Textural equilibria of iron sulfide liquids in partly molten silicate aggregates and their relevance to core formation scenarios. J. Geophys. Res. 105, 13555-13567.

Izenberg, N.R., Klima, R.L., Murchie, S.L., Blewett, D.T., Holsclaw, G.M., McClintock W.E., Malaret, E., Mauceri, C., Vilas, F., Sprague, A.L., Helbert, J., Domingue, D.L. Head III, J.W., Goudge, T.A., Solomon, S.C., Hibbitts, C.A., Dyar, M.D., 2014. The low-iron, reduced surface of Mercury as seen in spectral reflectance by MESSENGER. Icarus 228, 364-374

Jarosewich, E., 1990. Chemical analyses of meteorites: a compilation of stony and iron meteorite analyses. Meteoritics 25, 323-337.

Javoy, M., Kaminski, E., Guyot, F., Andrault, D., Sanloup, C., Moreira, M., Labrosse, S. Jambon, A., Agrinier, P., Davaille, A., Jaupart, C., 2010. The chemical composition of the Earth: enstatite chondrite models. Earth Planet. Sci. Lett. 293, 259-268.

Kerber, L., Head, J.W., Solomon, S.C., Murchie, S.L., Blewett, D.T., Wilson, L., 2009 Explosive volcanic eruptions on Mercury: eruption conditions, magma volatile content, and implications for interior volatile abundances. Earth Planet. Sci. Lett. $285,263-271$.

Le Feuvre, M., Wieczorek, M.A., 2011. Nonuniform cratering of the Moon and a revised crater chronology of the inner Solar system. Icarus 214, 1-20.

Li, C., Ripley, E.M., 2005. Empirical equations to predict the sulfur content of mafic magmas at sulfide saturation and applications to magmatic sulfide deposits. Miner. Depos. 40, 218-235.

Li, Y., Dasgupta, R., Tsuno, K., 2015. The effects of sulfur, silicon, water, and oxygen fugacity on carbon solubility and partitioning in Fe-rich alloy and silicate melt systems at $3 \mathrm{GPa}$ and $1600^{\circ} \mathrm{C}$ : implications for core-mantle differentiation and degassing of magma oceans and reduced planetary mantles. Earth Planet. Sci. Lett. $415,54-66$.

Malavergne, V., Tarrida, M., Combes, R., Bureau, H., Jones, J., Schwandt, C., 2007. New high-pressure and high-temperature metal/silicate partitioning of $\mathrm{U}$ and $\mathrm{Pb}$ : implications for the cores of the Earth and Mars. Geochim. Cosmochim. Acta 71 2637-2655.

Malavergne, V., Toplis, M.J., Berthet, S., Jones, J., 2010. Highly reducing conditions during core formation on Mercury: implications for internal structure and the origin of a magnetic field. Icarus 206, 199-209.

Malavergne, V., Cordier, P., Righter, K., Brunet, F., Zanda, B., Addad, A., Smith, T. Bureau, H., Surblé, S., Raepsaet, C., Charon, E., Hewins, R.H., 2014. How Mercury can be the most reduced terrestrial planet and still store iron in its mantle. Earth Planet. Sci. Lett. 394, 186-197.

Malavergne, V., Charon, E., Jones, J., Cordier, P., Righter, K., Deldicque, D., Hennet, L., 2016. The formation of nuggets of highly siderophile elements in quenched silicate melts at high temperatures: before or during the silicate quench? Earth Planet. Sci. Lett., 197-207.

Marchi, S., Mottola, S., Cremonese, G., Massironi, M., Martellato, E., 2009. A new chronology for the Moon and Mercury. Astron. J. 137, 4936-4948.

Mavrogenes, J.A., O'Neill, H.S., 1999. The relative effects of pressure, temperature and oxygen fugacity on the solubility of sulfide in mafic magmas. Geochim. Cosmochim. Acta 63, 1173-1180.

McClintock, W.E., Izenberg, N.R., Holsclaw, G.M., Blewett, D.T., Domingue, D.L., Head, J.W., Helbert, J., McCoy, T.J., Murchie, S.L., Robinson, M.S., Solomon, S.C., Sprague A.L., Vilas, F., 2008. Spectroscopic observations of Mercury's surface reflectance during MESSENGER's first Mercury flyby. Science 321, 62-65.

McCoy, T.J., Dickinson, T.L., Lofgren, G.E., 1999. Partial melting of the Indarch (EH4) meteorite: a textural, chemical, and phase relations view of melting and melt migration. Meteorit. Planet. Sci. 34, 735-746.

McCubbin, F.M., Riner, M.A., Vander Kaaden, K.E., Burkemper, L.K., 2012. Is Mercury a volatile-rich planet? Geophys. Res. Lett. 39, L09202.

McMillan, P.F., Wolf, G.H., 1995. Vibrational spectroscopy of silicate liquids. Rev. Mineral. Geochem. 32, 247-315.

Métrich, N., Berry, A.J., O'Neill, H.S., Susini, J., 2009. The oxidation state of sulfur in synthetic and natural glasses determined by X-ray absorption spectroscopy. Geochim. Cosmochim. Acta 73, 2382-2399.

Morard, G., Katsura, T., 2010. Pressure-temperature cartography of Fe-S-Si immiscible system. Geochim. Cosmochim. Acta 74, 3659-3667.

Mungall, J.E., Su, S., 2005. Interfacial tension between magmatic sulfide and silicate liquids: constraints on kinetics of sulfide liquation and sulfide migration through silicate rocks. Earth Planet. Sci. Lett. 234, 135-149.

Namur, O., Collinet, M., Charlier, B., Grove, T.L., Holtz, F., McCammon, C., 2016. Melting processes and mantle sources on Mercury's lavas. Earth Planet. Sci. Lett. 439, $117-128$

Neukum, G., Oberst, J., Hoffmann, H., Wagner, R., Ivanov, B.A., 2001. Geologic evolution and cratering of Mercury. Planet. Space Sci. 49, 1507-1521.

Nittler, L.R., Starr, R.D., Lev, L., McCoy, T.J., Burbine, T.H., Reedy, R.C., Trombka, J.I. Gorenstein, P., Squyres, S.W., Boynton, W.V., McClanahan, T.P., Bhangoo, J.S.
Clark, P.E., Murphy, M.E., Killen, R., 2001. X-ray fluorescence measurements of the surface elemental composition of asteroid 433 Eros. Meteorit. Planet. Sci. 36, 1673-1695.

Nittler, L.R., Starr, R.D., Weider, S.Z., McCoy, T.J., Boynton, W.V., Ebel, D.S., Ernst, C.M., Evans, L.G., Goldsten, J.O., Hamara, D.K., Lawrence, D.J., McNutt, R.L., Schlemm, C.E., Solomon, S.C., Sprague, A.L., 2011. The major-element composition of Mercury's surface from MESSENGER X-ray spectrometry. Science 333, 1847-1850.

Nittler, L.R., Weider, S.Z., Starr, R.D., Chabot, N.L., Denevi, B.W., Ernst, C.M., Goudge, T.A., Head, J.W., Helbert, J., Klima, R.L., McCoy, T.J., Solomon, S.C., 2014. Sulfurdepleted composition of Mercury's largest pyroclastic deposit: implications for explosive volcanism and surface reflectance on the innermost planet. In: 45th Lunar and Planetary Science Conference, p. 1391.

O'Neill, H.S., Mavrogenes, J.A., 2002. The sulfide capacity and the sulfur content at sulfide saturation of silicate melts at $1400^{\circ} \mathrm{C}$ and 1 bar. J. Petrol. 43, 1049-1087.

O'Neill, H.S.C., Eggins, S.M., 2002. The effect of melt composition on trace element partitioning: an experimental investigation of the activity coefficients of $\mathrm{FeO}$, $\mathrm{NiO}, \mathrm{CoO}, \mathrm{MoO}_{2}$ and $\mathrm{MoO}_{3}$ in silicate melts. Chem. Geol. 186, 151-181.

Ostrach, L.R., Robinson, M.S., Whitten, J.L., Fassett, C.I., Strom, R.G., Head, J.W., Solomon, S.C., 2015. Extent, age, and resurfacing history of the northern smooth plains on Mercury from MESSENGER observations. Icarus 250, 602-622.

Padovan, S., Wieczorek, M.A., Margot, J.-L., Tosi, N., Solomon, S.C., 2015. Thickness of the crust of Mercury from geoid-to-topography ratios. Geophys. Res. Lett. 42, 1029-1038.

Peplowski, P.N., Lawrence, D.J., Rhodes, E.A., Sprague, A.L., McCoy, T.J., Denevi, B.W., Evans, L.G., Head, J.W., Nittler, L.R., Solomon, S.C., Stockstill-Cahill, K.R., Weider, S.Z. 2012. Variations in the abundances of potassium and thorium on the surface of Mercury: results from the MESSENGER gamma-ray spectrometer. J. Geophys. Res., Planets 117, E00L04.

Peplowski, P.N., Evans, L.G., Stockstill-Cahill, K.R., Lawrence, D.J., Goldsten, J.O., McCoy, T.J., Nittler, L.R., Solomon, S.C., Sprague, A.L., Starr, R.D., Weider, S.Z., 2014. Enhanced sodium abundance in Mercury's North polar region revealed by the MESSENGER gamma-ray spectrometer. Icarus 228, 86-95.

Peplowski, P.N., Lawrence, D.J., Feldman, W.C., Goldsten, J.O., Bazell, D., Evans, L.G., Head, J.W., Nittler, L.R., Solomon, S.C., Weider, S.Z., 2015. Geochemical terranes of Mercury's northern hemisphere as revealed by MESSENGER neutron measurements. Icarus 253, 346-363.

Righter, K., Pando, K., Danielson, L.R., 2009. Experimental evidence for sulfur-rich martian magmas: implications for volcanism and surficial sulfur sources. Earth Planet. Sci. Lett. 288, 235-243.

Robie, R.A., Hemingway, B.S., 1995. Thermodynamic properties of minerals and related substances at $298.15 \mathrm{~K}$ and 1 bar pressure and at higher temperatures. U.S. Geol. Surv. Bull. 2131.

Rubie, D.C., Melosh, H.J., Reid, J.E., Liebske, C., Righter, K., 2003. Mechanisms of metal-silicate equilibration in the terrestrial magma ocean. Earth Planet. Sci. Lett. 205, 239-255

Shorttle, O., MacLennan, J., Lambart, S., 2014. Quantifying lithological variability in the mantle. Earth Planet. Sci. Lett. 395, 24-40.

Smith, D.E., Zuber, M.T., Phillips, R.J., Solomon, S.C., Hauck, S.A., Lemoine, F.G., Mazarico, E., Neumann, G.A., Peale, S.J., Margot, J.-L., Johnson, C.L., Torrence, M.H., Perry, M.E., Rowlands, D.D., Goossens, S., Head, J.W., Taylor, A.H., 2012. Gravity field and internal structure of Mercury from MESSENGER. Science 336, 214-217.

Sparks, R., Meyer, P., Sigurdsson, H., 1980. Density variation amongst mid-ocean ridge basalts: implications for magma mixing and the scarcity of primitive lavas. Earth Planet. Sci. Lett. 46, 419-430.

Sprague, A.L., Hunten, D.M., Lodders, K., 1995. Sulfur at Mercury, elemental at the poles and sulfides in the regolith. Icarus 118, 211-215.

Stockstill-Cahill, K.R. McCoy, T.J., Nittler, L.R., Weider, S.Z. Hauck, S.A., 2012. Magnesium-rich crustal compositions on Mercury: implications for magmatism from petrologic modeling. J. Geophys. Res. 117, E00L15.

Thomas, R.J., Rothery, D.A., Conway, S.J., Anand, M., 2014a. Long-lived explosive volcanism on Mercury. Geophys. Res. Lett. 41, 6084-6092.

Thomas, R.J., Rothery, D.A., Conway, S.J., Anand, M., 2014b. Mechanisms of explosive volcanism on Mercury: implications from its global distribution and morphology. J. Geophys. Res., Planets 119, 2239-2254.

Toplis, M.J., 2005. The thermodynamics of iron and magnesium partitioning between olivine and liquid: criteria for assessing and predicting equilibrium in natural and experimental systems. Contrib. Mineral. Petrol. 149, 22-39.

Vander Kaaden, K.E., McCubbin, F.M., 2015a. Sulfur solubility in silicate melts under highly reducing conditions relevant to Mercury. In: 46th Lunar and Planetary Science Conference, p. 1040.

Vander Kaaden, K.E., McCubbin, F.M., 2015b. Exotic crust formation on Mercury: consequences of a shallow, FeO-poor mantle. J. Geophys. Res., Planets 120, 195-209.

Vander Kaaden, K.E., McCubbin, F.M., 2016. The origin of boninites on Mercury: an experimental study of the northern volcanic plains lavas. Geochim. Cosmochim. Acta 173, 246-263.

Walter, M.J., Cottrell, E., 2013. Assessing uncertainty in geochemical models for core formation on Earth. Earth Planet. Sci. Lett. 365, 165-176.

Weider, S.Z., Nittler, L.R., Starr, R.D., Crapster-Pregont, E.J., Peplowski, P.N., Denevi, B.W., Head, J.W., Byrne, P.K., Hauck II, S.A., Ebel, D.S., Solomon, S.C., 2015. 
Evidence for geochemical terranes on Mercury: global mapping of major elements with MESSENGER's X-ray spectrometer. Earth Planet. Sci. Lett. 416, 109-120.

Weider, S.Z., Nittler, L.R., Starr, R.D., McCoy, T.J., Stockstill-Cahill, K.R., Byrne, P.K. Denevi, B.W., Head, J.W., Solomon, S.C., 2012. Chemical heterogeneity on Mercury's surface revealed by the MESSENGER X-ray spectrometer. J. Geophys. Res., Planets 117, E00L05.

Weider, S.Z., Nittler, L.R., Starr, R.D., McCoy, T.J., Solomon, S.C., 2014. Variations in the abundance of iron on Mercury's surface from MESSENGER X-ray spectrometer observations. Icarus 235, 170-186.
Weider, S.Z., Nittler, L.R., Murchie, S.L., Peplowski, P.N., McCoy, T.J., Kerber, L., Klimczak, C., Ernst, C.M., Goudge, T.A., Starr, R.D., Izenberg, N.R., Klima, R.L., Solomon, S.C., 2016. Evidence from MESSENGER for sulfur- and carbon-driven explosive volcanism on Mercury. Geophys. Res. Lett. 43, 3653-3661.

Wykes, J.L., O'Neill, H.S.C., Mavrogenes, J.A., 2015. The effect of FeO on the sulfur content at sulfide saturation (SCSS) and the selenium content at selenide saturation of silicate melts. J. Petrol. 56, 1407-1424.

Zolotov, M.Y., Sprague, A.L., Hauck, S.A., Nittler, L.R., Solomon, S.C., Weider, S.Z., 2013 The redox state, $\mathrm{FeO}$ content, and origin of sulfur-rich magmas on Mercury. J. Geophys. Res., Planets 118, 138-146. 